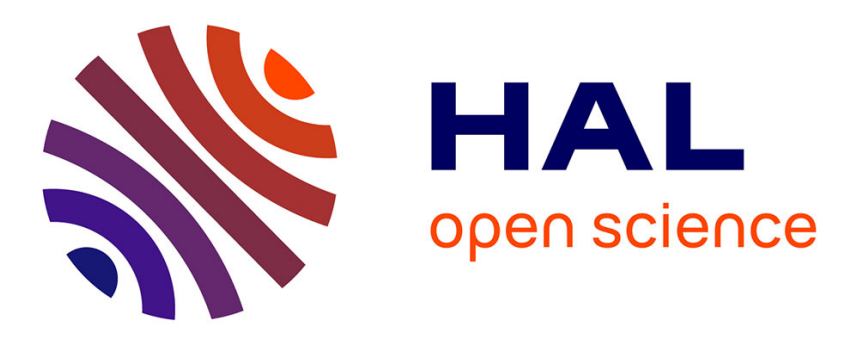

\title{
Dislocation-driven recrystallization in AZ31B magnesium alloy imaged by quasi-in situ EBSD in annealing experiments
}

\author{
Marco Lopez-Sanchez, Andrea Tommasi, F. Barou, R. Quey
}

\section{To cite this version:}

Marco Lopez-Sanchez, Andrea Tommasi, F. Barou, R. Quey. Dislocation-driven recrystallization in AZ31B magnesium alloy imaged by quasi-in situ EBSD in annealing experiments. Materials Characterization, 2020, 165, pp.110382. 10.1016/j.matchar.2020.110382 . hal-02777460

\section{HAL Id: hal-02777460 \\ https://hal.umontpellier.fr/hal-02777460}

Submitted on 14 Jul 2020

HAL is a multi-disciplinary open access archive for the deposit and dissemination of scientific research documents, whether they are published or not. The documents may come from teaching and research institutions in France or abroad, or from public or private research centers.
L'archive ouverte pluridisciplinaire HAL, est destinée au dépôt et à la diffusion de documents scientifiques de niveau recherche, publiés ou non, émanant des établissements d'enseignement et de recherche français ou étrangers, des laboratoires publics ou privés. 
Author copy of the final (peer-reviewed) version

Article published in Materials Characterization in May 2020. Please, reference to:

Lopez-Sanchez, M.A,, Tommasi, A. Bascou, F. Quey, R. (2020) Dislocation-driven recrystallization in

AZ31B magnesium alloy imaged by quasi-in situ EBSD in annealing experiments.

Materials Characterization: 165 (2020) 110382

https://doi.org/10.1016/j.matchar.2020.110382

\title{
Dislocation-driven recrystallization in AZ31B magnesium alloy imaged by quasi-in situ EBSD in annealing experiments
}

\author{
Marco A. Lopez-Sanchez ${ }^{\mathrm{a}, *}$, A. Tommasi ${ }^{\mathrm{a}}$, F. Barou ${ }^{\mathrm{a}}, \mathrm{R} . \mathrm{Quey}^{\mathrm{b}}$ \\ ${ }^{a}$ Géosciences Montpellier, Université de Montpellier \& CNRS, Place E. Bataillon, Montpellier, 34095 cedex 5, France \\ ${ }^{\mathrm{b}}$ Mines Saint-Étienne, Univ Lyon, CNRS, UMR 5307 LGF, Centre SMS, Saint-Étienne, 42023, France
}

\section{A R T I C L E I N F O}

\section{Keywords:}

Dislocation-driven recrystallization

EBSD

Grain boundary migration

Grain size

Dislocation density

Annealing

\begin{abstract}
A B S T R A C T
We led a series of annealing experiments with quasi-in situ electron backscattered diffraction (EBSD) measurements to characterize the effect of the deformation microstructure on static recrystallization. Six samples of commercial purity AZ31B magnesium alloy were deformed under different temperature and strain rate conditions to produce microstructures with variable dislocation densities and arrangements, and then heated at $300{ }^{\circ} \mathrm{C}$ $\left(0.64 T_{m}\right)$ for up to $6 \mathrm{~h}$ in several steps. All samples recrystallized by the growth of substructure-free grains, with nuclei mainly inherited from the deformed state. Recrystallization proceeded rapidly (minutes to hours), but remained incomplete in all cases. Using textural and microstructural proxies, we show that, under the studied experimental conditions, the stored energy associated with the dislocations controls the recrystallization kinetics. We observe a positive correlation between the initial average kernel average misorientation (KAM) and the recrystallization kinetics of each sample and, to a lesser extent, the recrystallized fraction at a given time. We also present direct evidence on how the stored energy in the vicinity of the recrystallization front controls grain boundary migration kinetics. Yet, the reduction in the stored energy alone cannot explain the stagnation of the recrystallization front and incomplete recrystallization.
\end{abstract}

\section{Introduction}

Annealing is of central importance in metallurgy to restore the ductility and control the mechanical properties of materials through recovery and recrystallization processes. In geosciences, annealing is the rule rather than the exception in the deep crust and mantle, modifying the microstructure and mechanical properties of rocks. Despite its importance and many experimental studies over the past decades, especially in metals, predicting the evolution of the microstructure during annealing remains a challenge [1-3], which is mostly due to the high number of phenomena and variables at play. There is therefore a critical need for new experiments and analyses determining the relative impact of these phenomena.

In highly deformed materials, annealing involves recovery, which decreases the stored energy by reorganizing and annihilating dislocations. However, the main phenomenon at play is recrystallization by nucleation and growth of substructure-free grains, ultimately lowering the stored energy of the material as the growth of new grains removes dislocations and reduces the grain boundary surface area. A better understanding of recrystallization therefore requires a better understanding of the main factors controlling the nucleation and grain growth kinetics. The nucleation rate is usually considered to be largely insensitive to the annealing temperature, but directly proportional to the stored energy [3,4]. The growth kinetics (the focus of this work) is described by the grain boundary migration rate, $v$, which is commonly expressed as:

$v=M F$

where $F$ is the driving force and $M$ is the (intrinsic) grain boundary mobility [5]. $F$ can be split into $F_{S}+F_{\sigma}$ [6], where $F_{S}$ is the stored energy in the deformed matrix and $F_{\sigma}$ is associated with the grain boundary curvature. It is well known that the grain boundary mobility $(M)$ depends largely on temperature, but also on intrinsic parameters such as misorientation or crystallography of the boundaries $[1,3,7]$. Grain boundary mobility may also be severely affected by extrinsic factors such as particles, solutes or pores, which cause pinning [8-11].

The material of interest in this work is the AZ31B magnesium alloy. This interest stems from three reasons. First, magnesium alloys have attracted increasing attention in the last two decades due to their low mass density compared to other conventional metallic materials, making them good candidates for the next generation of lightweight metallic materials. Second, the low crystal symmetry (hexagonal) and

\footnotetext{
* Corresponding author.

E-mail address: marco-antonio.lopez-sanchez@umontpellier.fr (M.A. Lopez-Sanchez).
} 
the strong viscoplastic anisotropy (dominant basal slip system) make magnesium a good analogue of major rock-forming minerals [12-14]. Third, magnesium alloys are appropriate for experiments with quasi-in situ characterization of the microstructure under low-pressure conditions in an SEM.

Previous works on the recrystallization of deformed AZ31B alloys have reported different phenomena: (i) texture evolution due to the preferential growth of grains with prismatic planes $\{11-20\}$ parallel to the extrusion direction [15-17], interpreted as a result of the anisotropy of the grain boundary mobility [18], (ii) recrystallization kinetics mainly controlled by the presence of twins and shear bands in the deformed microstructure [19-21], and (iii) evolution of the misorientation profiles across grain boundaries [18,21]. Two studies have explored the evolution of $\mathrm{Mg}$ alloys during annealing using quasi-in situ EBSD, one focusing on the relationship between twins and nucleation [21] and the other, on the effect of solute segregation on grain boundary mobility [22]. None of these studies, however, focused on the driving forces controlling grain boundary migration during the annealing of highly deformed materials, and, when analysing the evolution of grain boundary misorientation, the recrystallization front was not distinguished from the grain boundaries separating two deformed or two recrystallized grains. This is problematic since recent studies on highly deformed cubic materials, based on cutting-edge techniques, have shown only little (if any) effect of the misorientation or plane normal on the grain boundary mobility [6,23-27], but rather concluded that the spatial variations in stored energy and the local grain boundary curvature represent the two dominant factors controlling the migration of the recrystallization front.

To evaluate the driving forces controlling the grain boundary migration rate (v), it is necessary to measure the properties of the recrystallization front $[2,3]$ and to relate the dislocation density (or stored energy) and boundary curvature to the mobility. This requires local in situ observations associated with a more classical approach of averaging recrystallization variables. Ideally, it also requires discriminating the effects of the driving forces from those of the grain boundary mobility and, hence, excluding the effect of extrinsic factors.

In this paper, our goal is to characterize the effects of the variations of stored energy and the local grain boundary curvature on the recrystallization kinetics of highly deformed $\mathrm{Mg}$ alloys. To do so, we designed an experiment that meets the following prerequisites: (i) the deformed (pre-annealed) samples have different microstructures and dislocation contents but are otherwise similar (same fraction of secondary particles, etc), (ii) all samples are subjected to the same annealing sequence (in particular, to the same temperature), and (iii) the evolution of the microstructures is observed in detail, by in situ EBSD.

\section{Materials and methods}

We used a commercial-purity AZ31B magnesium alloy ( $\sim 96 \% \mathrm{Mg}$, $\sim 3 \% \mathrm{Al}, \sim 1 \% \mathrm{Zn}$ ) with a recrystallized microstructure. The apparent mean grain size, in terms of the diameter of the circle of equivalent surface area, was $\sim 9 \mu \mathrm{m}$ (mode $\sim 5 \mu \mathrm{m}$ ). Most grains had an internal misorientation spread lower than $1 \%$, indicating that grains were initially nearly single-crystalline, and the initial twin boundary fraction was lower than $1 \%$. The material had an intense basal texture, with a maximum of the orientation distribution function of 8 (see Supplementary material).

\subsection{Deformation experiments}

The samples were machined for deformation in plane strain compression along different directions with respect to the basal texture (Fig. 1). Two samples had their dominant c-axis along the compression direction (CD), one sample had its dominant c-axis along the transverse direction (TD), and three samples had their dominant c-axis along the elongation direction (ED). Samples of $10 \times 8 \times 10 \mathrm{~mm}$ (along ED, TD and $\mathrm{CD}$, respectively) were deformed using a channel-die compression device [28]. Before deformation, the samples were carbon-coated using a graphite spray and wrapped in polytetrafluoroethylene (Teflon) films to reduce friction effects during deformation, and then heated up to the target temperature in $30 \mathrm{~s}$ to $1 \mathrm{~min}$. After deformation, the samples were water-quenched within $1 \mathrm{~s}$. The relatively high heating and cooling rates of the system minimize thermally-induced microstructure changes [28].

The samples were deformed at two different temperatures: 250 and $300{ }^{\circ} \mathrm{C}\left(0.59\right.$ and $0.64 T_{m}$, respectively, where $T_{m}$ is the melting temperature), and two different strain rates: $10^{-2}$ and $10^{-1} \mathrm{~s}^{-1}$. To prevent, as much as possible, recrystallization during deformation (dynamic recrystallization), von Mises strains were limited to $\sim 0.12$, except for two samples, for which von Mises strains were 0.25 . Small volumes of dynamically recrystallized grains developed during the deformation experiment (Table 1). The resulting maximal stresses during deformation ranged from $81 \mathrm{MPa}$ to $164 \mathrm{MPa}$ (Fig. 1, Table 1). In the following, samples are named after the maximal stress they developed during deformation (e.g. "S81" for "sample with maximal stress of $81 \mathrm{MPa}$ "). The key microstructural features of the deformed samples are provided in Table 1 and more details can be found in Supplementary Material. In the following, the deformed samples constitute the "initial state" of our samples and will be referred as such, as we analyse annealing microstructures as a function of the attributes of the initial, deformed microstructures.

\subsection{Annealing experiments}

The deformed samples were cut in half parallel to the CD-ED plane (Fig. 1a), and the resulting internal surfaces were mechanically polished using SiC papers and oil-based diamond suspensions (down to $0.25 \mu \mathrm{m}$ ) and then electro-polished using a solution composed of $5 \%$ nitric acid (50\%), 15\% acetic acid, $20 \%$ distilled water and $60 \%$ ethanol, at $\sim 5{ }^{\circ} \mathrm{C}$ and in two steps ( $3 \mathrm{~V}$ for $30 \mathrm{~s}$ and $1.5 \mathrm{~V}$ for $45 \mathrm{~s}$ ). The sample microstructures were observed on this surface before and during annealing, with no need for new polishing after each annealing.

The in situ annealing experiments were carried out in a CamScan X500-FE CrystalProbe SEM-EBSD chamber. Samples were fixed to an inhouse ceramic stage with three thermocouples attached; one to the heater surface, one to the sample surface, and one to the ceramic stage holder (see Supplementary Material). Calibrations showed average heating and cooling rates from 25 to $300{ }^{\circ} \mathrm{C}$ under low vacuum $(\sim 2 \mathrm{~Pa})$ of $77^{\circ} \mathrm{C} \cdot \mathrm{min}^{-1}$ and $1.5-6{ }^{\circ} \mathrm{C} \cdot \mathrm{min}^{-1}$, respectively. The temperature difference between the base and the surface of the sample was about $50{ }^{\circ} \mathrm{C}$ for a $2-\mathrm{mm}$ thick sample. For each sample, we conducted one annealing experiment consisting of four to six thermal cycles, each followed by EBSD measurements at $T<50{ }^{\circ} \mathrm{C}$ for a quasi-in situ monitoring. Since a steady-state temperature at the surface could not be reached, the time during which the base of the heater remained higher than $200{ }^{\circ} \mathrm{C}$ (which corresponds to $\sim 150{ }^{\circ} \mathrm{C}$ at the surface) was considered as annealing time. Cumulative annealing times are provided in Table 2 and heating-cooling curves in the Supplementary Material.

\subsection{EBSD analysis and microstructural proxies}

After each annealing step, two orientation maps were acquired: a general map, with a step size of $0.7 \mu \mathrm{m}$ and a grid of $347 \times 282$ pixels $\left(\sim 243 \times 197 \mu^{2}\right)$, and a high-spatial-resolution map in a smaller region, with a step size of $0.4 \mu \mathrm{m}$ and grids of between $299 \times 162$ pixels $\left(\sim 120 \times 65 \mu^{2}\right)$ and $285 \times 270$ pixels $\left(\sim 114 \times 108 \mu \mathrm{m}^{2}\right)$. General and high-resolution orientation maps were acquired in $\sim 40$ and $\sim 20 \mathrm{~min}$, respectively. EBSD patterns were indexed using the Refined Accuracy algorithm in AZtec v.3.2 software of HKL Technology, leading to an angular resolution of 0.1 to $0.5^{\circ}$. For most samples, the raw indexing rate was higher than $90 \%$ (see Supplementary Material for details). 

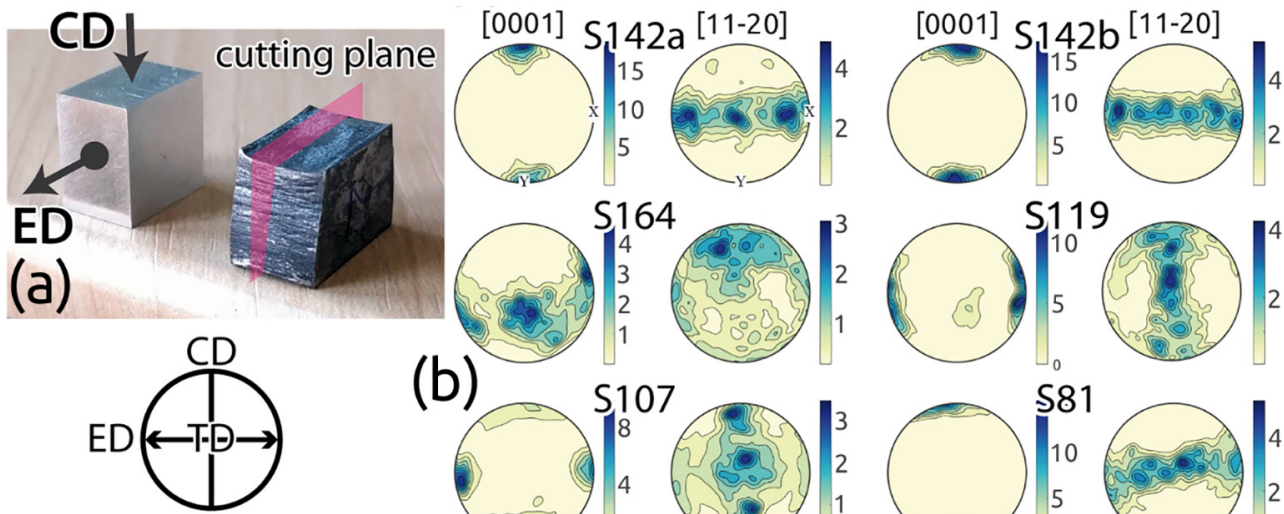

(b)
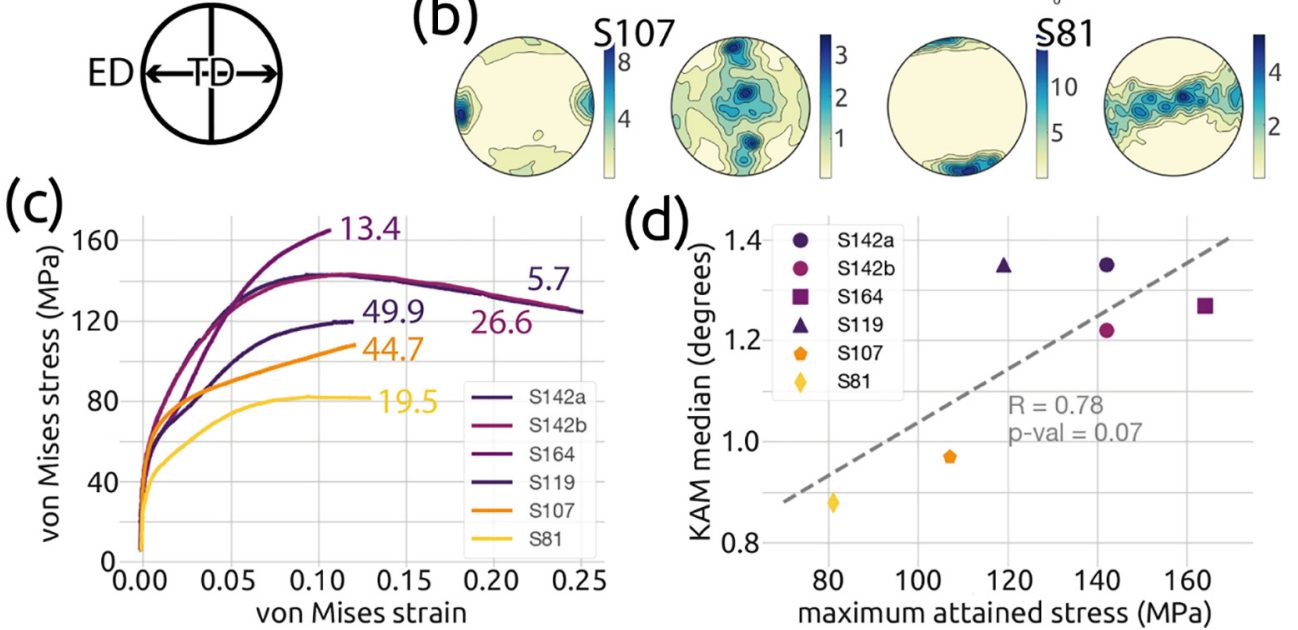

(d)

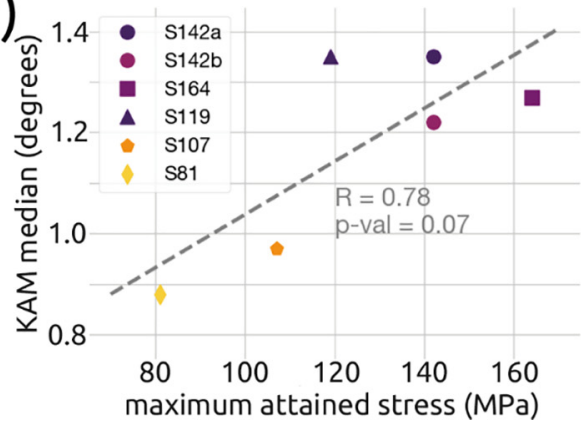

Fig. 1. Deformation experiments and resulting microstructures and textures. (a) Sample deformation coordinate system. ED: extension direction, TD: transverse direction, CD: compression direction. (b) Deformation textures represented as pole figures (equalarea projection) with intensities in multiples of a uniform distribution (half-width $5^{\circ}$ ). (c) von Mises logarithmic strain-stress curves (numbers indicate the percentage of twin boundaries after deformation in each sample). (d) Average KAM as a function of the maximal stress.

Table 1

Deformation experiments conditions and microstructural parameters of the deformed samples.

\begin{tabular}{|c|c|c|c|c|c|c|c|c|c|c|c|c|}
\hline \multirow[t]{2}{*}{ Sample ref. } & \multirow[t]{2}{*}{$\mathrm{T}\left({ }^{\circ} \mathrm{C}\right)$} & \multirow{2}{*}{$\begin{array}{l}\text { Strain rate } \\
\left(\mathrm{s}^{-1}\right)\end{array}$} & \multirow{2}{*}{$\begin{array}{l}\text { Final von Mises } \\
\text { shortening }\end{array}$} & \multirow{2}{*}{$\begin{array}{l}\text { c-Axis max. } \\
\text { orientation }\end{array}$} & \multirow{2}{*}{$\begin{array}{l}\text { Peak stress } \\
(\mathrm{MPa})\end{array}$} & \multirow{2}{*}{$\begin{array}{l}\text { DRX fraction } \\
(\%)\end{array}$} & \multirow{2}{*}{$\begin{array}{l}\text { Twin boundaries } \\
(\%)\end{array}$} & \multicolumn{2}{|c|}{ KAM (degrees) } & \multicolumn{2}{|c|}{ Grain size $(\mu \mathrm{m})$} & \multirow{2}{*}{$\begin{array}{l}\text { Texture } \\
\text { strength } \\
\text { J-index }\end{array}$} \\
\hline & & & & & & & & Median & $\mathrm{IQR}^{\mathrm{b}}$ & $\begin{array}{l}\text { Geo. } \\
\text { mean }\end{array}$ & Mode & \\
\hline S164 & 250 & 0.1 & 0.11 & Along ND & 164 & 0.3 & 13.4 & 1.26 & 0.84 & 4.8 & 3.4 & 2.1 \\
\hline S142a & 250 & 0.01 & 0.25 & Along CD & 142 & $0.5^{\mathrm{a}}$ & 26.6 & 1.33 & 0.86 & 2.5 & 2.0 & 8.4 \\
\hline S142b & 300 & 0.1 & 0.24 & Along CD & 142 & 1.4 & 5.7 & 1.21 & 0.80 & 3.1 & 2.1 & 9.5 \\
\hline S119 & 250 & 0.01 & 0.12 & Along ED & 119 & 0.1 & 49.9 & 1.34 & 0.82 & 3.1 & 2.1 & 6.8 \\
\hline S107 & 300 & 0.1 & 0.12 & Along ED & 107 & 0.4 & 44.7 & 0.97 & 0.68 & 4.1 & 2.4 & 3.5 \\
\hline S81 & 300 & 0.01 & 0.13 & Along CD & 81 & 1.0 & 19.5 & 0.86 & 0.75 & 5.7 & 3.7 & 7.5 \\
\hline
\end{tabular}

a Not well constrained due to low EBSD indexing in recrystallized areas.

b IQR - Interquartile range.

Table 2

Cumulative annealing times for the different samples. The annealing time corresponds to the time above $200{ }^{\circ} \mathrm{C}\left(\sim 150{ }^{\circ} \mathrm{C}\right.$ at the sample surface).

\begin{tabular}{lllllll}
\hline \multirow{2}{*}{ Sample } & \multicolumn{2}{l}{ Annealing times (mm:ss) } & & & \\
\cline { 2 - 7 } & Stage 1 & Stage 2 & Stage 3 & Stage 3' & Stage 4 & Stage 5 \\
\hline 164 & $18: 49$ & $39: 43$ & $82: 39$ & $149: 45$ & $274: 36$ & $398: 08$ \\
$142 \mathrm{a}$ & $19: 40$ & $40: 48$ & $83: 06$ & - & $267: 56$ & - \\
$142 \mathrm{~b}$ & $18: 28$ & $39: 33$ & $81: 40$ & - & $266: 08$ & - \\
119 & $19: 21$ & $40: 52$ & $83: 16$ & - & $246: 07$ & - \\
107 & $19: 22$ & $39: 55$ & $82: 17$ & - & $267: 10$ & - \\
81 & $18: 10$ & $39: 19$ & $81: 56$ & - & $268: 13$ & - \\
\hline
\end{tabular}

The resulting EBSD data were analysed using the MTEX toolbox v5.1.0 [29,30] and in-house codes provided in Supplementary Material. The overall procedure is summarized in Fig. 2. Grains were reconstructed using the fast multiscale clustering algorithm [31], which allowed to track the evolution of both the apparent (2D) grain size and the grain boundary roughness (see Appendices A and B for definitions). Boundary roughness was estimated with the solidity parameter, $(S)$, but we present the data as $S_{i}=1-S$, so that the grain boundary roughness takes a minimal value of 0 for grains with straight faces and values up to 1 as the roughness of the grain boundary increases.

A commonly used metric, the "kernel average misorientation (KAM)", was chosen as a proxy to quantify the local lattice distortion. The KAM is defined as the average value of the misorientation angles between a pixel and its neighbours. It correlates, to first order, with the density of geometrically necessary dislocations and the associated stored energy [32-35]. We used the KAM to locate and estimate the magnitude and gradients of the stored energy and to track recovery in sub-structured grains.

The KAM calculation involves two parameters: the misorientation threshold and the kernel size [36,37]. The misorientation threshold enables one to exclude grain boundaries from the calculation and was set to $5^{\circ}$. The kernel size depends on the number of pixel neighbours (also known as the "KAM order") and the pixel size. In the present study, the balance between a proper spatial resolution and low KAM uncertainty (resulting from the angular uncertainty and the presence of non-indexed points) has been achieved by using a 2nd-order kernel for the medium-resolution maps and a 4th-order kernel for the high-resolution maps. This choice leads to fairly similar kernel sizes (or radii) 


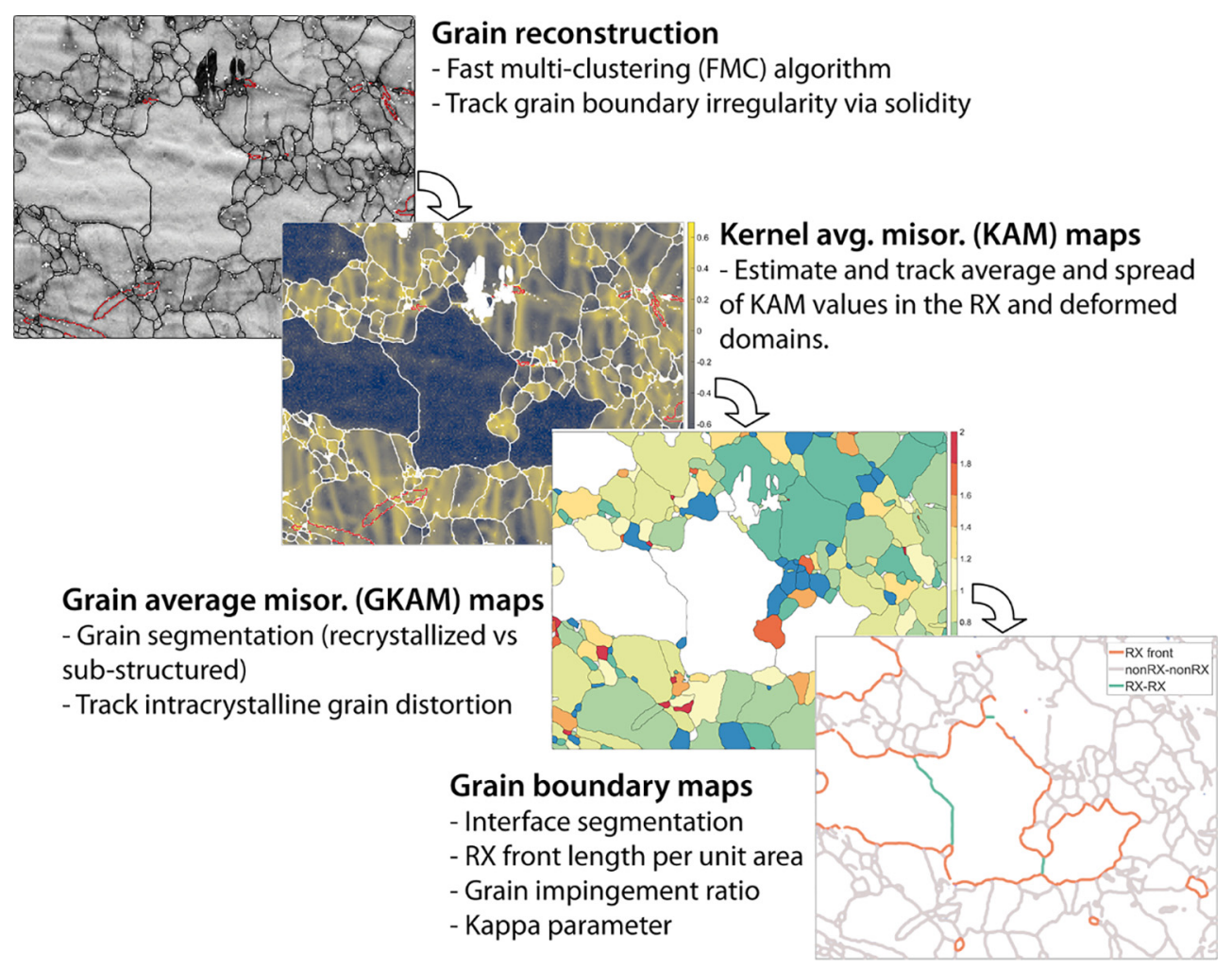

Fig. 2. Sequential steps used in the analysis of the annealed microstructures.

of 1.6 and $1.4 \mu \mathrm{m}$, respectively (hence allowing direct comparisons between the two types of maps).

The orientation distribution within a grain was also quantified using the grain kernel average misorientation (GKAM). The GKAM was used to distinguish recrystallized from non-recrystallized, sub-structured grains. In general, the distribution of KAMs values within a grain shows a strong asymmetry, which was accounted for using appropriate (robust) metrics: the sample median and the interquartile range. Working from the KAM and band contrast EBSD maps, a threshold value of $\sim 0.2-0.3 \%$ was chosen for the GKAM to segment the recrystallized grains. Most recrystallized grains showed KAMs of the order of the typical EBSD angular resolution, which confirms that recrystallized grains are virtually dislocation-free.

Once the recrystallized grains were segmented, grain boundaries were classified into three types: RX-RX, SS-SS and RX-SS, where RX-RX boundaries separate recrystallized grains, SS-SS boundaries separate sub-structured grains, and RX-SS boundaries constitute the recrystallization front. We followed the evolution during annealing of the recrystallization front length per unit area, $S_{V}$, and of the grain impingement ratio, which is the ratio of the length of the RX-RX boundaries to the total boundary length of the recrystallized grains, RX$\mathrm{RX}+\mathrm{RX}-\mathrm{SS}$. We also use microstructure path plots to follow the microstructural evolution of the samples [38,39].

If we consider that the elastic forces associated with a dislocation decay as the inverse to the distance, the dislocations closer to the recrystallization front have a stronger effect on it. To determine how local differences in dislocation density (or stored energy) drive the mobility of the recrystallization front, we define a new proxy, $\kappa$, which estimates the KAM gradient across the recrystallization front,

$\kappa=\arctan \frac{\left|K A M_{p x 1}-K A M_{p x 2}\right|}{b_{t}}$

where $\mathrm{KAM}_{\mathrm{px} 1,2}$ are the KAM values of the adjacent pixels on both sides of the recrystallization front and $b_{t}$ the boundary thickness (considered equal to $1 \mathrm{~nm}$ ). Fig. 3 displays an example of a $\kappa$ map. Since we compare data for EBSD maps with similar resolutions, we ignored the step size in the $\kappa$ computation (Eq. (2)). $\kappa$ allows to (i) determine if local differences of stored energy in the vicinity of the recrystallization front correlates with the presence of protrusions and retrusions and (ii) gauge the effect of the stored energy by correlating the average $\kappa$ and the average recrystallization front velocity.

\subsection{Kinetics of recrystallization and grain growth}

We used logistic (Verhulst) growth curves [40] to model the evolution of the recrystallized fraction $\left(X_{V}\right)$ over logarithmic time and to estimate the recrystallization rate, $\dot{G}$. The average speed of the recrystallization front as a function of time was estimated using the CahnHagel spatially averaged boundary migration rate method, as detailed in Appendix C and Ref. [41]. Grain growth kinetics was estimated using standard procedures detailed in Appendix C.

\section{Results}

\subsection{Evolution of the recrystallized fraction}

The evolution of the recrystallized fraction with time varies markedly across samples (Figs. 4, 5a). In the four deformed samples with average KAMs higher than $1.2^{\circ}$, the recrystallization fraction increased very rapidly in the first annealing step $(<19 \mathrm{~min}$ ) and then only moderately to end up forming a plateau for most samples (Fig. 5a). S119, which shows the fastest recrystallization, reached a recrystallized fraction plateau after $40 \mathrm{~min}$ of annealing, at a recrystallized fraction of $93 \%$. S142a and S142b reached recrystallized fraction plateaus at a similar time of $80 \mathrm{~min}$ of annealing, though at very different recrystallized fractions of 83 and 51\%, respectively. In contrast, S164 exhibits a continuously increasing recrystallized fraction until the end of the annealing experiment ( $400 \mathrm{~min}$ ), where the recrystallized attains $66 \%$. The deformed samples with average KAMs lower than 1 showed a continuous increase of recrystallized fraction during the annealing 


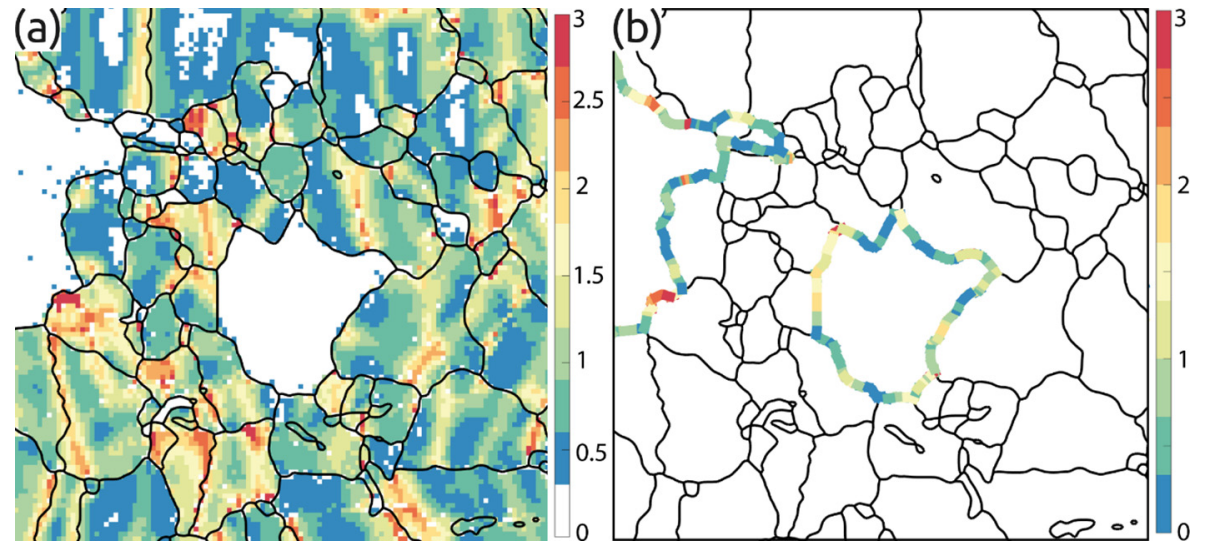

Fig. 3. The $\kappa$ proxy. (a) Reference KAM map using a discrete colour scale, numbers are expressed in degrees. (b) Associated $\kappa^{\prime}$ values (in ${ }^{\circ} \mathrm{nm}{ }^{-1}$ ) along the recrystallization front.

experiment, although the process significantly slowed down after $80 \mathrm{~min}$ (Fig. 5a). The recrystallized fractions within $80 \mathrm{~min}$ of annealing are noticeably lower in these samples. The recrystallized fraction in S81 remains significantly lower than in the other samples at all annealing times. However, the final recrystallized fraction for S107, with an initial (deformed state) average KAM of $0.97^{\circ}$, is higher than those observed for S142b and S164, which have initial average KAMs of $1.21^{\circ}$ and $1.26^{\circ}$, respectively (Fig. 5a).

The evolution of the recrystallized fractions, which never attain $100 \%$ in the present experiments, cannot be represented by the standard Johnson-Mehl-Avrami-Kolmogorov (JMAK) model, which assumes full recrystallization at infinite time. We therefore used logistic curves over logarithmic time to fit the experimental measurements (Fig. 5b, see Appendix C2). The fitting procedure provides maximum, final recrystallized fractions ranging from 19 to 93\% (Table 3). Two curves show unreliable trends, which can be explained by problems in the experimental measurements. For S164, the measured recrystallized fractions align almost linearly in the semi-logarithmic plot (Fig. 5b), which results in a logistic curve with a sigmoidal shape that departs significantly from the others. We think that this anomalous trend may have been caused by the image distortion issues in some EBSD maps (see Supplementary Material). For S119, the very fast recrystallization prevented us from recording any data before the plateau is reached. Thus the fitting procedure provides a robust estimate of the recrystallization plateau (parameter $L$ ), but the curve shape and location are poorly constrained (parameters $k$ and $m$, see Table 3 ).

The recrystallized fraction at each annealing time correlates positively with the average initial KAM for all samples (Fig. 5c). This correlation becomes weaker with time (Fig. $5 \mathrm{c}$ ), with $\mathrm{R}$ values decreasing from 0.90 at $19 \mathrm{~min}$ to 0.81 at $269 \mathrm{~min}$. This can largely be explained by the off-trend path followed by sample 107 which, despite low initial recrystallization rates, after about $70 \mathrm{~min}$ of annealing attains higher recrystallized fractions than two samples with higher average initial KAMs. The recrystallized fraction at each annealing time also somewhat correlates with the initial grain size (see Supplementary Material). However, this correlation can be questioned, since the p-value of the regressions is unsuitable. Moreover, initial grain sizes and KAMs also correlate positively. Thus, this apparent correlation may just result from the correlation of both grain size and recrystallized fraction with the average initial KAM.

The series of GKAM maps provided in Fig. 6 illustrates the evolution of the recrystallization front during annealing. The recrystallization front tends to move towards areas that contain grains with high GKAMs. Grains with low GKAMs tend to persist during recrystallization, as the recrystallization front slows down or stay put as it meets them. However, transitory stagnation of the recrystallization front may also happen at the contact with a few grains with high GKAMs (the black circle in Fig. 6).

\subsection{Evolution of the grain boundary roughness}

The time series of segmented grain boundary maps (Fig. 7) shows that recrystallized grains growing with low impingement ratios (i.e., with a low fraction of RX-RX grain boundaries, see Section 2.3) develop irregular shapes, increasing their boundary roughness with time. Overall, the surface of the recrystallization front remains very irregular during annealing (Figs. 6 and 7). In contrast, RX-RX boundaries generally appear smooth or straight and show equal-angle triple junctions (Fig. 7).

The different behaviour between the RX-RX and RX-SS boundaries accounts for (i) a general increase with time of the average grain boundary roughness as long as the grain impingement ratio remains lower than $\sim 0.4$ and (ii) a decrease or stagnation of the overall grain boundary roughness at impingement ratios higher than $\sim 0.4$ (Fig. 8 a).

\subsection{Recrystallization front features}

The evolution of the recrystallization front length per unit area $\left(S_{V}\right)$ as a function of the recrystallized fraction shows that the six samples exhibited different trends (Fig. 8b). Four samples attained maximal $S_{V}$ values at recrystallized fractions within the range $40-60 \%$, indicating symmetrical microstructure evolution paths. The samples with initial KAMs higher than $1.2^{\circ}$ reached similar maximal $S_{V}$ values of $0.06 \mu \mathrm{m}^{-1}$, whereas $\mathrm{S} 107$, with an initial KAM of $0.97^{\circ}$, reached a maximal $S_{V}$ value lower than $0.045 \mu \mathrm{m}^{-1}$. This indicates that samples with higher initial KAMs develop recrystallization fronts of greater lengths per unit area, which implies higher rates of (non-clustered) nucleation, a more irregular recrystallization front surface, or a combination of both.

The KAM and $\kappa$ maps illustrate how the gradients of stored energy control the progression of the recrystallization front on scales lower than the grain size (Fig. 9). The recrystallization front tends to develop protrusions towards high KAM regions (boundary segments with high $\kappa$ values) and retrusions towards low KAM regions (boundary segments with low $\kappa$ values). Still, exceptions occur (cf. red arrow in Fig. 9a, b).

\subsection{Evolution of the stored energy associated with dislocations}

To characterize the evolution of the stored energy associated with dislocations in the samples, we analyse the evolution of the average KAM within the sub-structured domain during annealing. In samples with high initial KAMs $\left(>1.2^{\circ}\right)$, the average KAM within the substructured domain decreases rapidly in the first annealing step ( $<19 \mathrm{~min}$ ) followed by a slow monotonic decrease (Fig. 10a). The two 

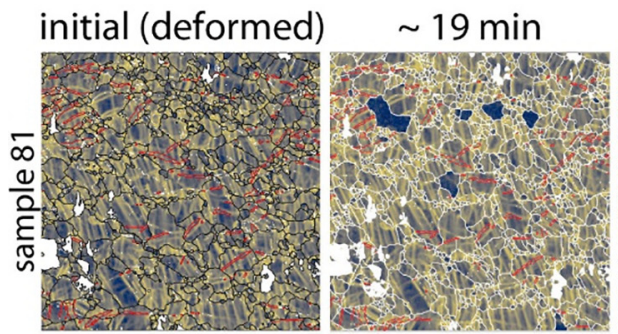

$\sim 40 \mathrm{~min}$

$\sim 82 \min$

$269 \min ^{*}$
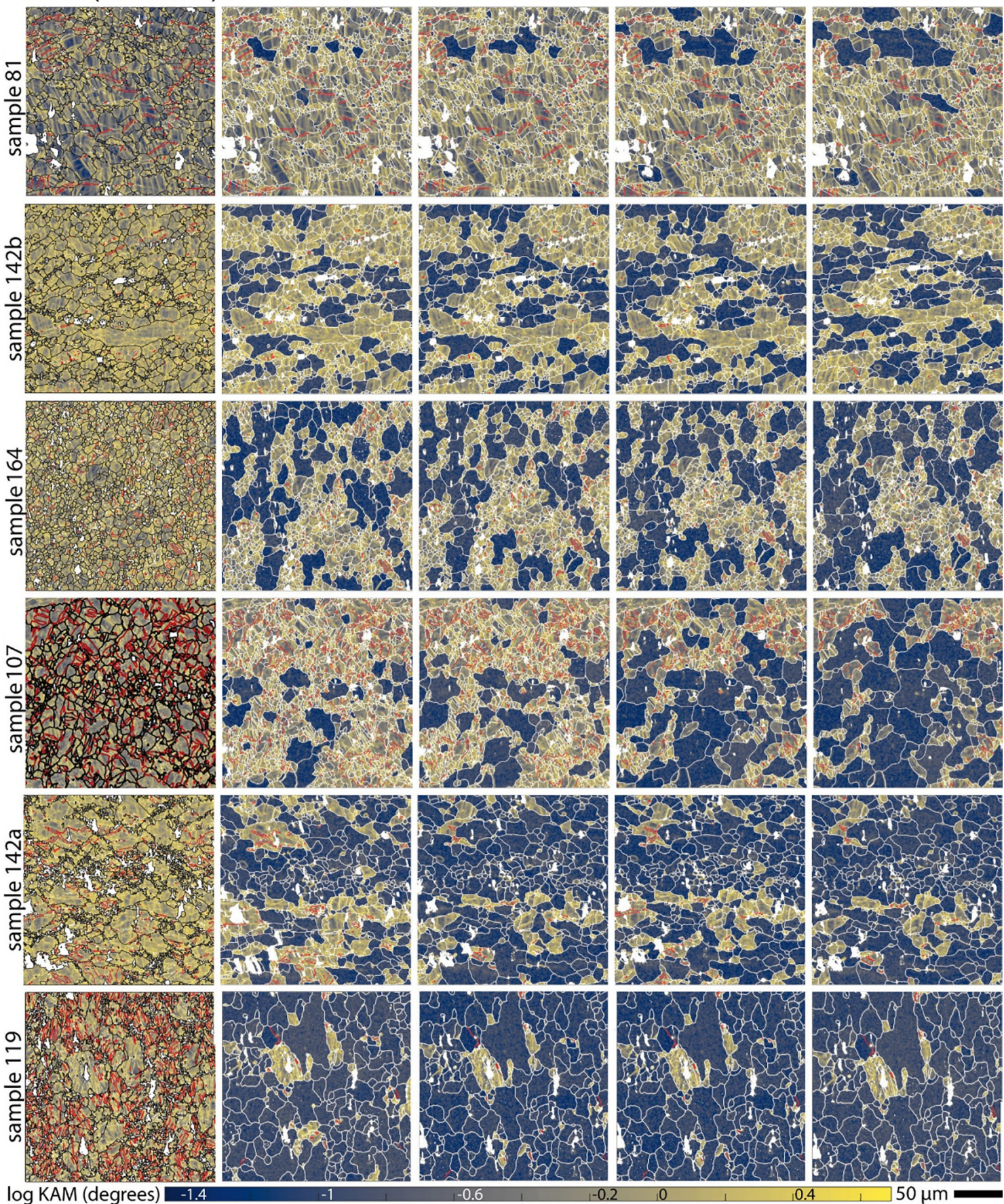

$\log$ KAM (degrees) -1.4

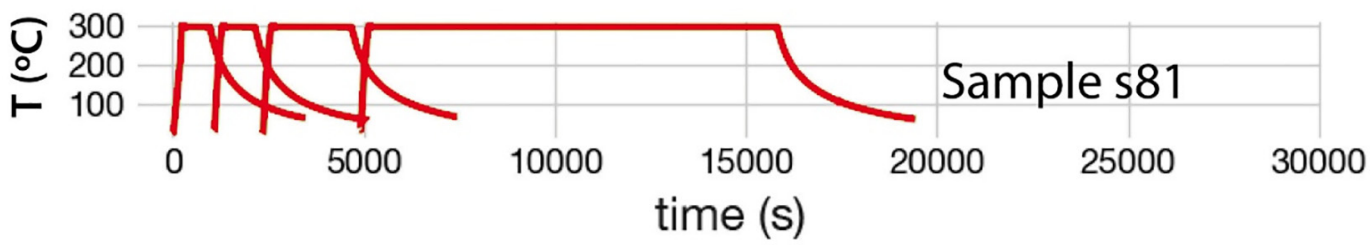

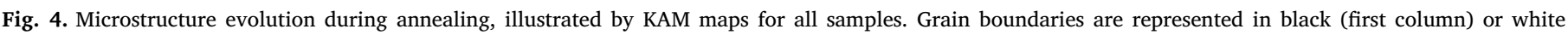

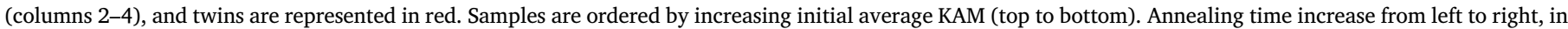

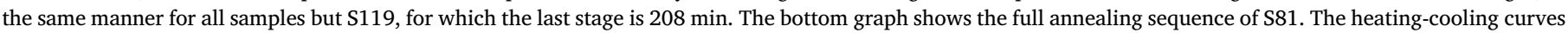

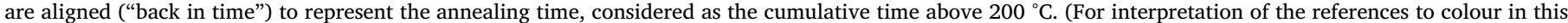
figure legend, the reader is referred to the web version of this article.) 

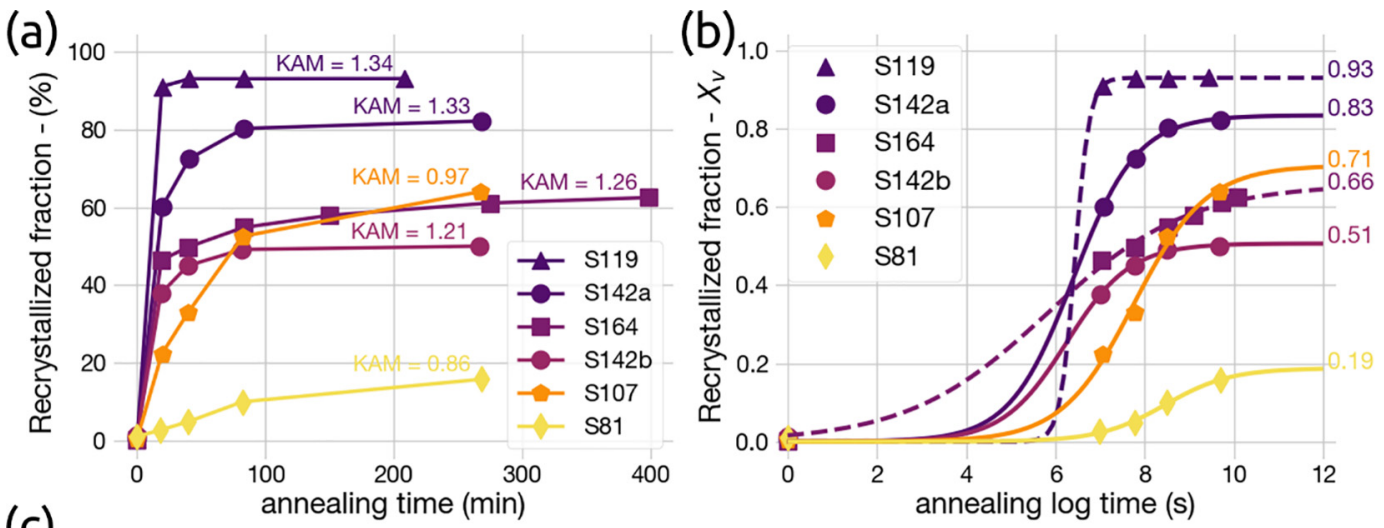

(c)

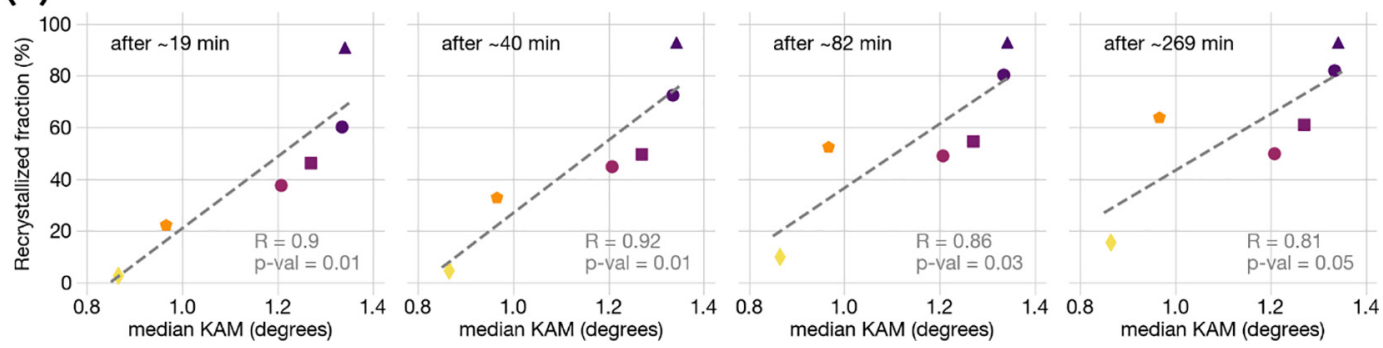

Fig. 5. Recrystallized fraction evolution during annealing. (a) Recrystallized fraction evolution with time. For each sample, the initial average KAM is indicated. (b) Recrystallized fraction evolution with logarithmic time, fitted by logistic curves. For each sample, the maximum recrystallized fraction provided by the model is indicated. (c) Evolution of the relation between the initial average KAM and the recrystallized fraction, at each annealing time.

Table 3

Logistic curve parameters fitting the evolution of the recrystallized fraction with time in the different annealing experiments.

\begin{tabular}{llclcll}
\hline Sample & $\mathrm{k}$ & C.V. (\%) & $\mathrm{L}$ & C.V. (\%) & $\mathrm{m}$ & C.V. (\%) \\
\hline S164 & 0.6 & 19 & 0.7 & 3.9 & 5.8 & 3.6 \\
S142a & 1.4 & 14 & 0.8 & 1.4 & 6.4 & 1.4 \\
S142b & 1.4 & 30 & 0.5 & 2.7 & 6.2 & 3.5 \\
S119 & 6.1 & 104 & 0.9 & 0.6 & 6.4 & 9 \\
S107 & 1.2 & 21 & 0.7 & 6.2 & 7.8 & 2 \\
S81 & 1.6 & 24 & 0.2 & 16.3 & 8.5 & 4 \\
\hline
\end{tabular}

$\mathrm{k}$ : curve shape parameter; L: maximum $\mathrm{RX}$ fraction; $\mathrm{m}$ : location of the inflexion point; C.V.: coefficients of variation of the different fitted parameters. samples with lower initial KAMs $\left(<1^{\circ}\right.$, S81 and S107) show different evolutions to each other. S81 show an evolution similar to one of the samples with initial KAMs higher than 1.2, except for the first annealing step, for which the decrease in average KAM is lower. In contrast, S107 exhibits a steady decrease in average KAM throughout annealing. A similar difference between (S107) and the others had already been observed on the evolution of the recrystallized fraction (see Section 3.1). The decrease of stored energy in the sub-structured domain can result from two complementary factors: recovery, which reorganizes and annihilates dislocations, and selective growth of new grains in the high stored-energy regions leading to a decrease of area of the substructured domain (indirect effect). Evidence for the second process is the stronger decrease in the average KAM in the sub-structured domain (Fig. 10a) than in the individual grains (see Supplementary Material),

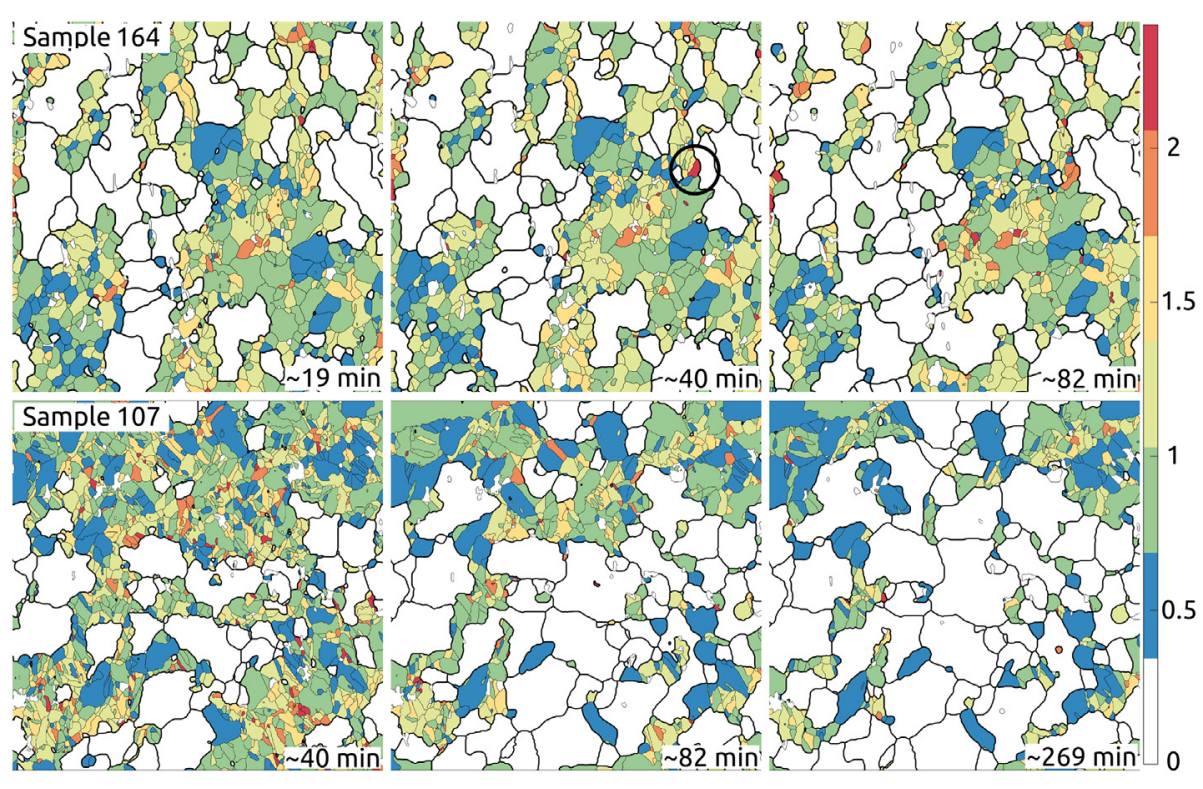

Fig. 6. Recrystallization front evolution during annealing, shown as GKAM maps for S164 and S107. Note the irregularity of the recrystallization front, how the recrystallization front tends to move towards areas containing grains with high GKAMs (red to yellow-green grains), and how grains with low GKAMs (blue and green grains) tend to persist during annealing. The black circle in the upper central panel indicates the counter-example of a grain with a high GKAM that persists during annealing. (For interpretation of the references to colour in this figure legend, the reader is referred to the web version of this article.) 


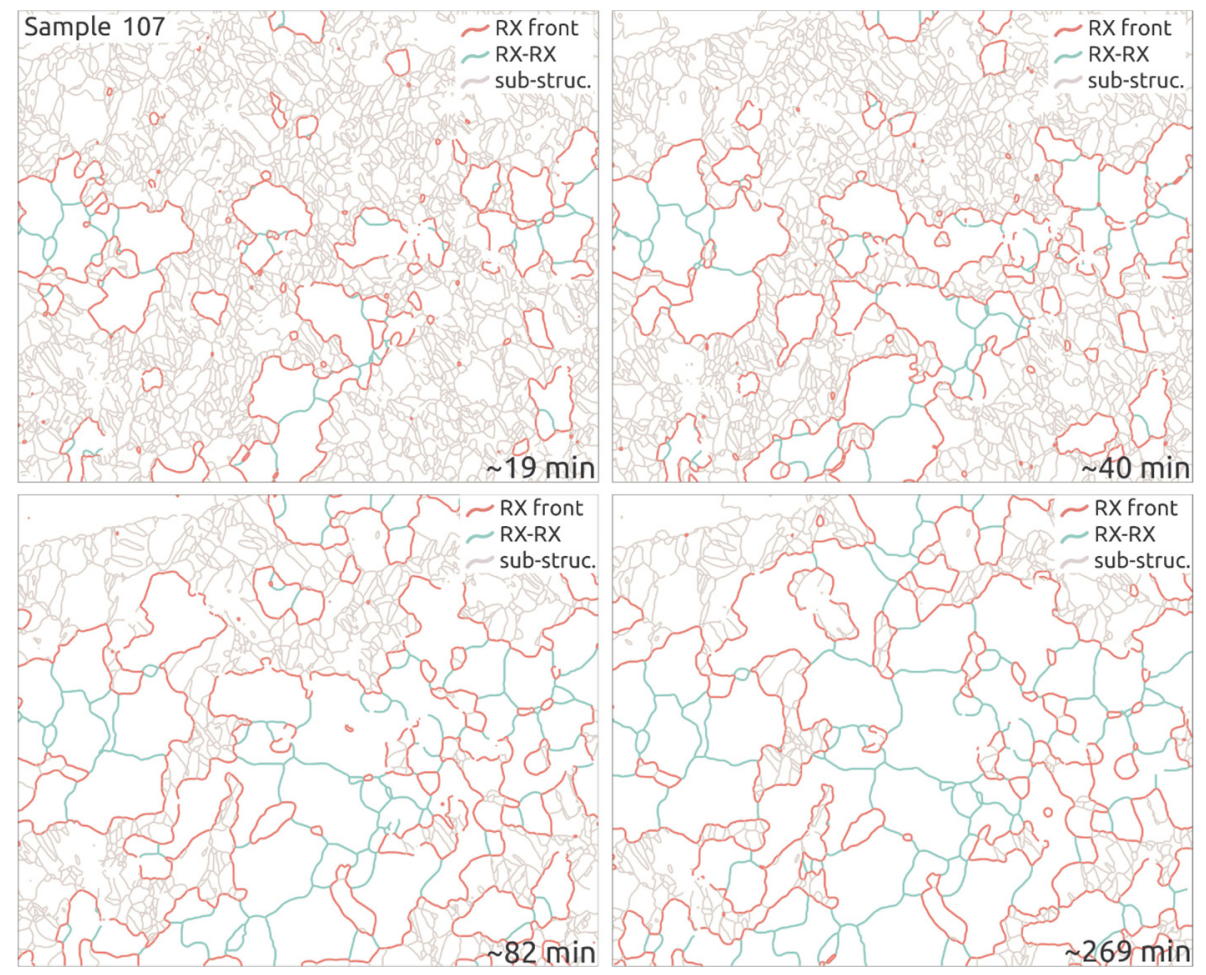

Fig. 7. Evolution of the different grain boundary types during annealing (sample S107; maps at 19, 40, 82 and 269 min of annealing).

which is also qualitatively shown by the series of KGAM maps (Fig. 6).

The evolution of the average $\kappa$ values at different annealing times (Fig. 10b) illustrates the evolution of the stored energy associated with dislocations in the vicinity of the recrystallization front. The average $\kappa$ values show a similar evolution as the average KAMs, even if the initial fast decrease step is missing, as the recrystallization front cannot be defined at the initial state. Different evolutions of the average $\kappa$ values are observed for samples with low $\left(<1^{\circ}\right)$ and high $\left(>1.2^{\circ}\right)$ KAMs. However, the $\kappa$ paths of all samples run approximately parallel (except for S142b, probably due to acquisition issues during the last EBSD scan, as already mentioned). This contrasts with the average KAMs, which had markedly different evolutions for the two samples of low initial KAMs, indicating that although the average stored energies differ between the two samples, their distributions in the vicinity of the recrystallization front are similar.

\subsection{Evolution of the recrystallized grain size}

The increase of recrystallized grain size slows down after $80 \mathrm{~min}$ of annealing for all samples (Fig. 11a, Table 4). The three samples developing the highest maximal stresses (S164, S142a, and S142b) exhibit similar evolutions and final values of the recrystallized grain sizes (Fig. 11a, Table 4). The samples with the lowest and highest final recrystallized fractions, S81 and S119, respectively, show similar evolutions, but different final recrystallized grain sizes (Fig. 11a, Table 4).

Power-law curves appropriately fit the evolution of average recrystallized grain sizes for all samples but S107, which, despite its high correlation coefficient $(>0.9)$, shows a significantly higher standard error in the fit than the others (Fig. 11a, b, Table 4). Excluding this sample, the grain growth exponents ( $n$ ) range from 7 to 18 (Table 5).

\subsection{Texture evolution and misorientation along the $R X$ front}

Sub-structured and recrystallized grains show different textures and texture evolutions among samples, as the samples were compressed at different directions with respect to the strong as-received basal texture (Fig. 12a and Supplementary Material). The deformation and the postannealing textures show that dynamically and statically recrystallized grains display similar overall patterns, but with different intensities (Fig. 12a). For instance, recrystallized grains in S81, S142b and S142a (deformed with their dominant c-axis along $\mathrm{CD}$ ) tend to develop a maximum of $\{1210\}$ close to ED (Fig. 12 and Supplementary Material). This maximum, which is already present in the dynamically recrystallized grains, is reinforced during annealing. In S119 and S107 (deformed with the dominant-axis along ED), dynamically and statically recrystallized grains show textures characterized by concentration (a)

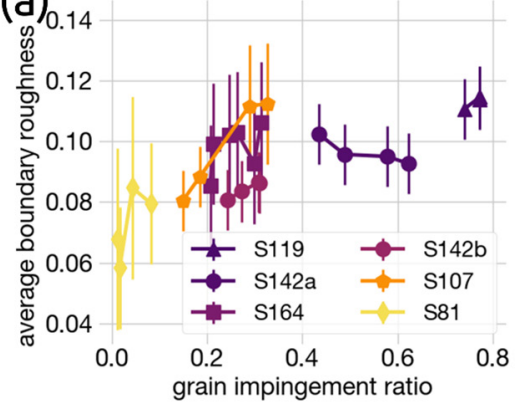

(b)

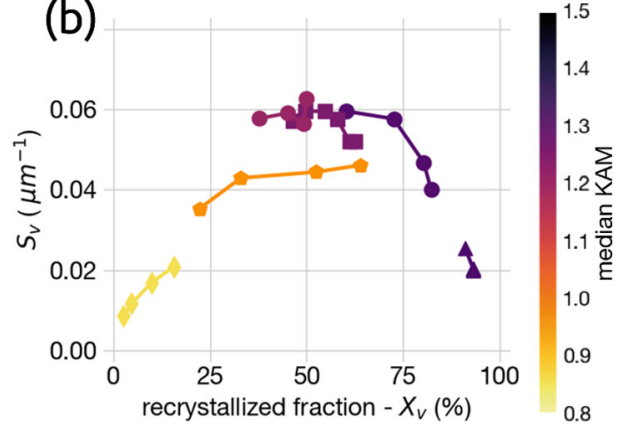

Fig. 8. (a) Average grain boundary roughness vs. overall grain impingement ratio. Ascending paths indicate that grain boundaries become more irregular with time on average. Error bars are 2- $\sigma$ errors. (b) Microstructure evolution path for the different samples characterized by the evolution of the recrystallization front length per unit area $\left(\mathrm{S}_{\mathrm{V}}\right)$ as a function of the recrystallization fraction $\left(\mathrm{X}_{\mathrm{V}}\right)$. 

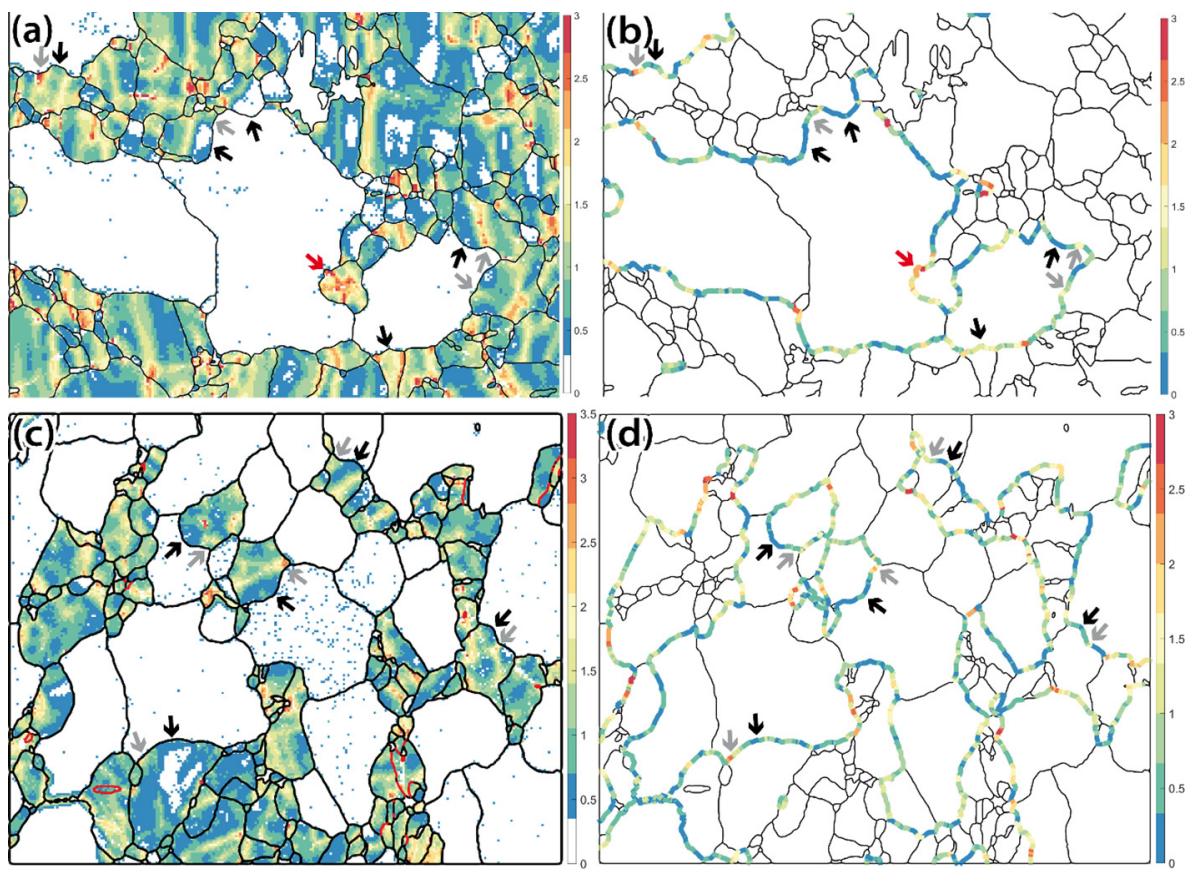

Fig. 9. KAM and $\kappa$ maps illustrating how the local gradients in dislocation density control the progression of the recrystallization front. (a, c) High-resolution KAM maps for S81 and S164. Arrows indicate examples of protrusions (grey arrows) and retrusions (black arrows) towards the sub-structured domain due to high and low KAM regions in the vicinity of the recrystallization front, respectively. (b, d) $\kappa$ values along the recrystallization front for the same regions. The red arrow in (a) and (b) shows the counter-example of a retrusion of the recrystallization front located in the vicinity of a high stored energy region. KAMs are in degrees and $\kappa$ values in degree $\mathrm{nm}^{-1}$. (For interpretation of the references to colour in this figure legend, the reader is referred to the web version of this article.)

of [0001] (c-axis) around ED, forming a girdle with an opening of $10-20^{\circ}$, and development of a secondary incomplete fibre of [0001] at a high angle to ED. However, texture evolution during annealing in these two samples differs markedly. In S119, the [0001] girdle at a low angle to ED is reinforced, indicating preferential growth of this texture component, whereas, in S107, the texture is weakened, with disappearance of the initial [0001] maximum parallel to ED. Lastly, in S164 (deformed with the c-axis maximum along TD), recrystallization does not significantly change the deformed texture, which is weak (see Supplementary Material).

The misorientation angle distributions along the recrystallization front (but also along with RX-RX interfaces) differ significantly from one sample to another and evolve only slightly during annealing (Fig. 12b). This implies that specific grain boundaries do not influence the recrystallization process.

\section{Discussion}

The microstructural evolution observed for all samples indicates that, under the tested annealing conditions, recrystallization in AZ31 $\mathrm{Mg}$ alloys develops by nucleation and growth of substructure-free grains at the expenses of the deformed (sub-structured) grains. This process is fast (minutes to hours) and exhausts before completion in all cases.

\subsection{Dislocation-driven $\left(F_{S}\right)$ vs curvature-driven $\left(F_{\sigma}\right)$ grain boundary migration}

The experiments provided several microstructural pieces of evidence of the major influence of the stored energy associated with dislocations on grain boundary mobility and recrystallization kinetics, as indirectly quantified by the KAM and $k$ proxies. These are (i) the strong positive correlation between the recrystallized fraction and the initial average KAMs, especially in the first stages of annealing (Fig. 5c), (ii) the tendency of the recrystallization front to move preferentially towards areas or grains with high KAMs and GKAMs (Fig. 6), (iii) the tendency of grain boundary segments adjacent to areas with low KAMs to stay put and the high survival rate of the grains with low GKAMs (Fig. 6), and (iv) the correspondence between high/low $k$ values and protrusions/retrusions in the recrystallization front (Fig. 9).

The roughness of the recrystallized grain boundaries increases with time as long as recrystallized grains grow mainly at the expenses of the deformed material, which globally corresponds to grain impingement ratios lower than $\sim 0.4$ (Fig. 8a). Recrystallization therefore develops essentially by the progression of a highly irregular recrystallization front (Fig. 7). The absence of an overall reduction in the (a)

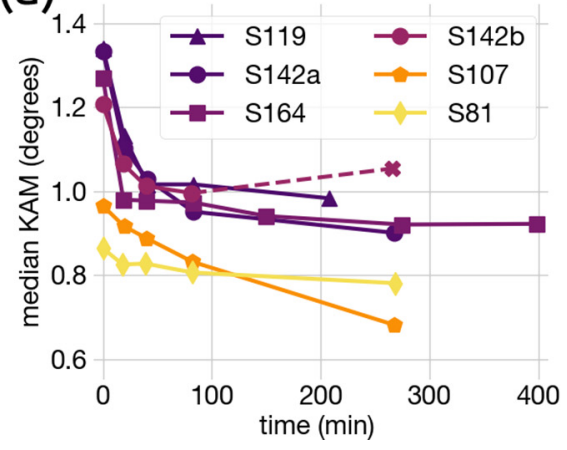

(b)

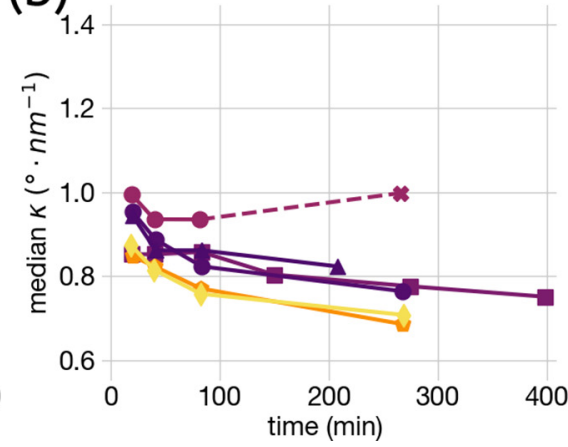

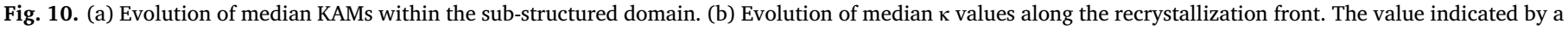
cross corresponds to an EBSD map with acquisition artefacts (a severe distortion issue), which lead to high uncertainty in the estimation of KAM and $\kappa$ values. 

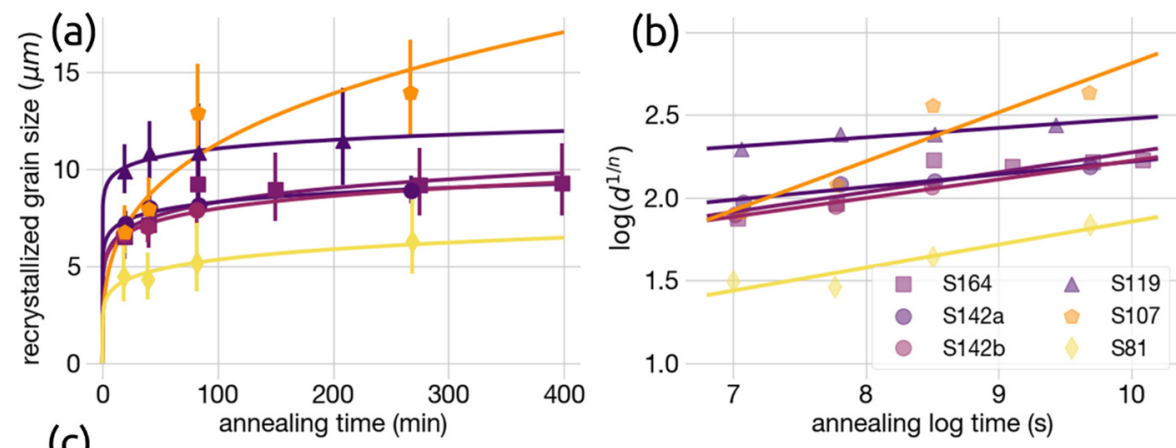

Fig. 11. Evolution of the recrystallized grain size during annealing. (a, b) Grain size as a function of annealing time with grain growth curves fitted in (left) linear-linear and (right) log-log scales. On (a), error bars represent 2- $\sigma$ errors. (c) The relation between the initial (deformed) average KAM and the recrystallized grain size as a function of time.

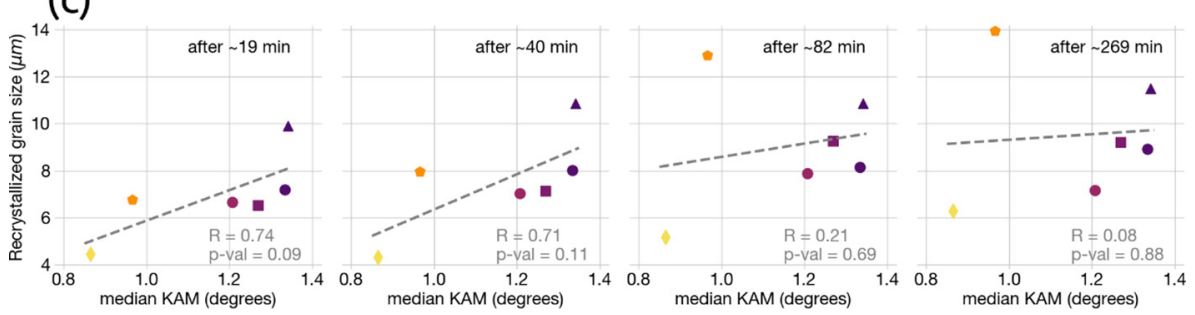

recrystallization front curvature during recrystallization further supports that the stored energy associated to dislocations, not the grainboundary curvature, is the main factor that drives the progression of the recrystallization front.

Similar generation of rough interfaces with protrusions/retrusions during static recrystallization of highly sub-structured aggregates was previously observed in cubic-symmetry metals such as high-purity aluminium $[6,25,26]$ or nickel [23]. In halite, it was also observed at moderate temperatures $\left(\sim 0.55 T_{m}\right)$, but face-parallel grain boundary migration predominated at high temperatures $\left(\sim 0.65 T_{m}\right)$ [42]. Studies on aluminium $[6,25,26]$ interpreted the protrusions/retrusions in a similar way as in this work, as promoted by local variations in stored density, although a role of the local decrease of curvature in the retrusion segments once they reach a critical curvature was also suggested [6]. The limited spatial resolution of our EBSD maps prevented us from evaluating such a very local effect, however.

\subsection{Influence of the stored energy on recrystallization rates and final recrystallized fractions}

Monitoring the evolution of the recrystallized fraction with time (at similar annealing temperatures) revealed (i) an increasing then decreasing recrystallization rate with logarithmic time, (ii) a positive correlation between the initial average KAM and the recrystallized fraction, particularly at the beginning of recrystallization, (iii) highly variable recrystallization rates among samples, and (iv) different evolutions of the recrystallization rates for the two samples with average KAMs lower than $1^{\circ}$.

The evolution of the recrystallization rate $(\dot{G})$ during annealing (Fig. 13) indicates that the samples with the highest initial average KAMs recrystallized faster. This can also be seen from the negative
Table 5

Recrystallized grain growth fitting parameters.

\begin{tabular}{llrllll}
\hline Sample ref. & $\mathrm{K}\left(\mu \mathrm{m}^{2} / \mathrm{s}\right)$ & \multicolumn{1}{c}{$\mathrm{n}$} & $1 / \mathrm{n}$ & $\mathrm{R}^{\mathrm{a}}$ & $p$-val $^{\mathrm{a}}$ & Std. err. $^{\mathrm{a}}$ \\
\hline S164 & $7.86 \mathrm{E}+03$ & 8.34 & 0.12 & 0.89 & 0.02 & 0.03 \\
S142a & $1.58 \mathrm{E}+08$ & 13.02 & 0.08 & 0.97 & 0.03 & 0.01 \\
S142b $^{\mathrm{b}}$ & $1.70 \mathrm{E}+04$ & 8.88 & 0.11 & 0.97 & 0.14 & 0.03 \\
S119 & $4.92 \mathrm{E}+13$ & 17.69 & 0.06 & 0.94 & 0.06 & 0.02 \\
S107 & $6.08 \mathrm{E}-01$ & 3.38 & 0.30 & 0.93 & 0.07 & 0.08 \\
S81 & $2.90 \mathrm{E}+01$ & 7.20 & 0.14 & 0.94 & 0.06 & 0.04 \\
\hline
\end{tabular}

${ }^{\mathrm{a}} \mathrm{R}$ : correlation coefficient, $p$-val: two-sided $p$-values, and std. err.: the standard error of linear regression on log-log plot (Fig. 11b).

${ }^{\mathrm{b}}$ Last measure (stage 4) not taken into account due to EBSD map artefacts.

correlation between the initial average KAM and the annealing time corresponding to $50 \%$ of the final maximum recrystallization fraction (Fig. 13b) (i.e., the inflexion point of the logistic curve in Fig. 5b). The final recrystallized fraction does not always correlate with faster kinetics (Fig. 13c). A clear example arises when comparing S142b and S107 (Fig. 13), where the sample with a slower kinetics, S107, reaches a higher final recrystallized fraction.

The analysis of the evolution of the recrystallized rates (Fig. 13) and recrystallization fractions (Fig. 5) shows that, in general, the recrystallization rate and the final recrystallized fraction correlate with the initial KAM and the maximal stress in the deformation experiment. However, two samples (S107 and S119) deviate from this trend. The possible reasons behind this are discussed below. Samples 107 and 119 were deformed with their dominant c-axis along ED. As a consequence, they developed higher twinning fractions than the others $(\sim 50 \%$ vs. $\leq 26 \%$, Table 1, Fig. 4). The higher twinning fractions in the deformed microstructures might explain more effective recrystallization during

Table 4

Average size of recrystallized grains.

\begin{tabular}{|c|c|c|c|c|c|c|c|c|c|c|c|c|}
\hline \multirow[t]{2}{*}{ Time } & \multicolumn{2}{|l|}{ S164 } & \multicolumn{2}{|l|}{ S142a } & \multicolumn{2}{|l|}{ S142b } & \multicolumn{2}{|l|}{ S119 } & \multicolumn{2}{|l|}{ S107 } & \multicolumn{2}{|l|}{ S81 } \\
\hline & Geo. mean & $\mathrm{n}$ & Geo. mean & $\mathrm{n}$ & Geo. mean & $\mathrm{n}$ & Geo. mean & $\mathrm{n}$ & Geo. mean & $\mathrm{n}$ & Geo. mean & $\mathrm{n}$ \\
\hline $19 \mathrm{~min}$ & 6.52 & 119 & 7.19 & 266 & 6.67 & 171 & 9.91 & 195 & 6.78 & 72 & 4.47 & 21 \\
\hline $40 \mathrm{~min}$ & 7.14 & 113 & 8.02 & 277 & 7.03 & 166 & 10.86 & 159 & 7.97 & 81 & 4.33 & 31 \\
\hline $80 \mathrm{~min}$ & 9.26 & 105 & 8.15 & 272 & 7.89 & 160 & 10.86 & 159 & 12.91 & 67 & 5.18 & 31 \\
\hline $270 \mathrm{~min}$ & 9.2 & 97 & 8.92 & 251 & 7.18 & 193 & 11.49 & 153 & 13.95 & 68 & 6.28 & 36 \\
\hline $398 \mathrm{~min}$ & 9.3 & 101 & & & & & & & & & & \\
\hline
\end{tabular}

$\mathrm{n}$ : number of grains. 

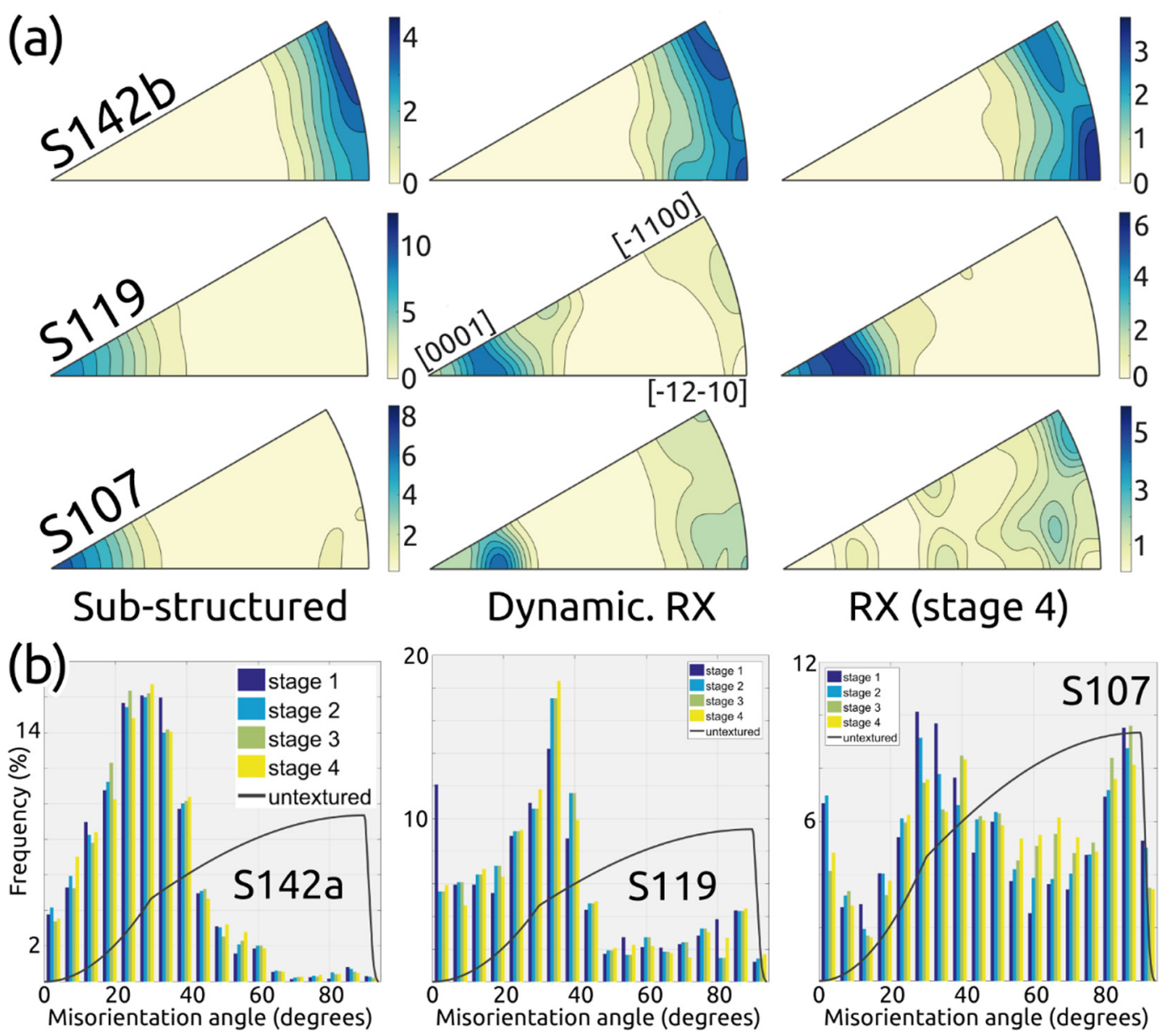

RX (stage 4)

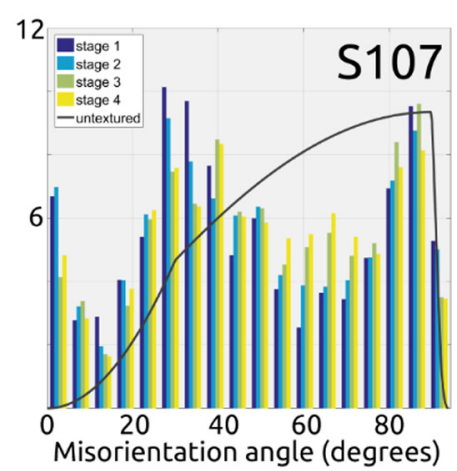

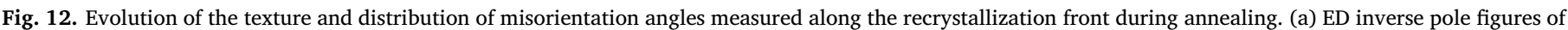

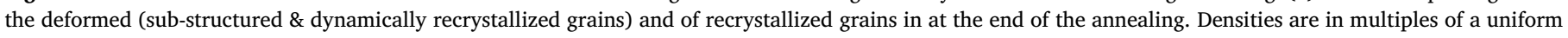

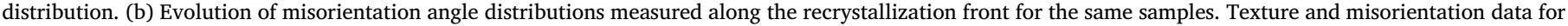
all samples are provided in the Supplementary Material.

annealing (both samples achieved higher final recrystallized fractions than others, with higher initial stored energies, as indicated by their higher initial KAMs). Previous works reported that compression and crossing twins on AZ31B Mg alloys act as nucleation sites for recrystallization $[19,21,43]$. However, the two samples display different evolutions, which point to different processes at play. S119 displays extremely fast initial recrystallization kinetics, achieving a maximal recrystallized fraction of $93 \%$ in $<40 \mathrm{~min}$ of annealing (Fig. 5). The analysis of the microstructural evolution for this sample highlights some correlation between the presence of twin boundaries and the occurrence of recrystallization (compare the microstructures before and after 19 min of annealing in Fig. 4). On the other hand, S107 displays much lower initial recrystallization rates, resulting in a higher final recrystallized fraction than samples with higher initial KAMs and recrystallization rates (e.g. S164 and S142b in Fig. 5a, b). Analysis of the microstructural evolution for this sample does not show any clear spatial correlation between high twin boundary density in the deformed state and recrystallization (Fig. 4). Indeed, in this sample, as in the remaining ones, many twin boundaries are preserved during annealing (Fig. 4). Moreover, for the other samples, the absence of a positive correlation between the initial twin fraction and the final recrystallized fraction or the recrystallization kinetics suggests that this is a secondorder factor in our experiments.

The reasons for the different kinetics of microstructural evolution of S107 during annealing remain unclear. Recrystallization is slower and continues up until the end of the experiment, producing an almost
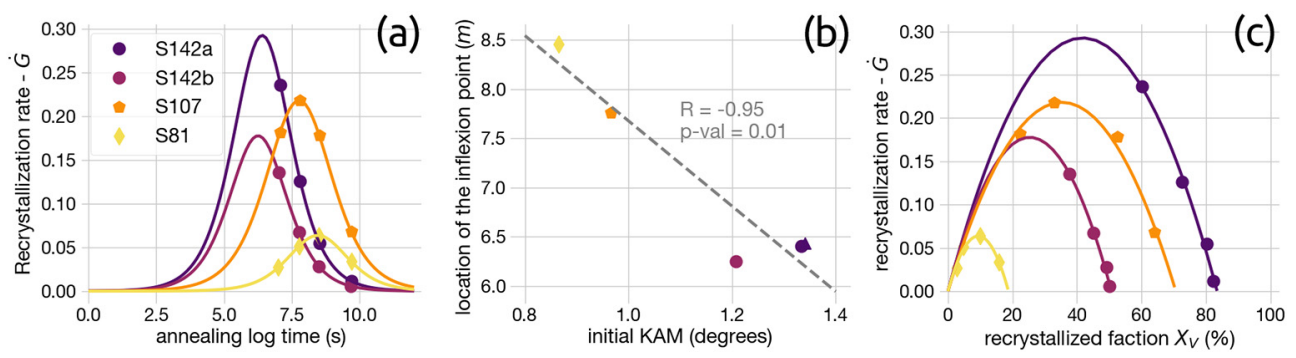

Fig. 13. Evolution of recrystallization rates determined from the evolution of the recrystallized fractions as represented by logistic curves. (a) Recrystallization rate evolution with logarithmic time. Markers are plotted at experimental measurement times. Note that curves for samples with low initial KAM (yellow-orange) are located to the right, which means slower kinetics. (b) Time corresponding to the maximum growth rate (or, equivalently, $50 \%$ of the maximum recrystallization fraction, or the inflexion point of the curve) as a function of the initial average KAM. (c) Recrystallization rate as a function of recrystallized fraction. Note that, in (a) and (c), fast kinetics and maximum attained recrystallization rate are not correlated. (For interpretation of the references to colour in this figure legend, the reader is referred to the web version of this article.) 

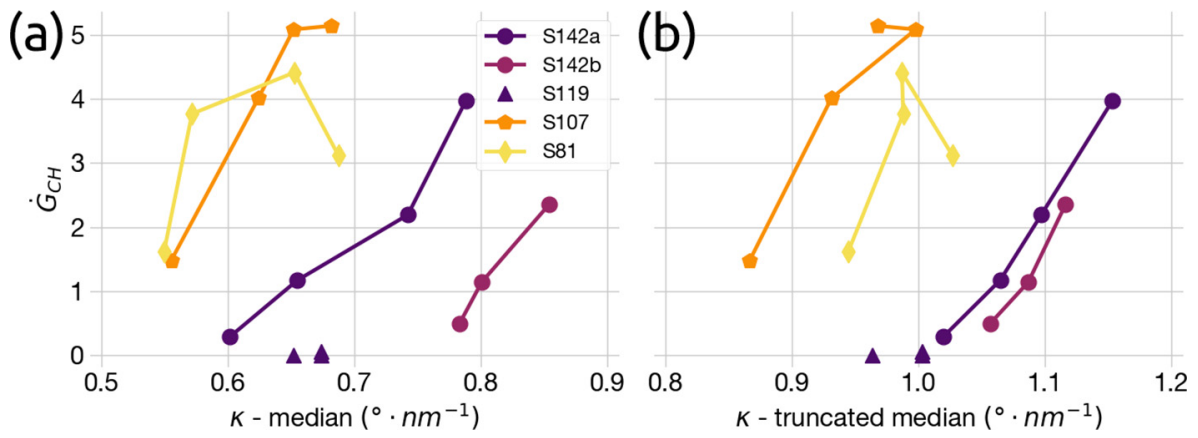

Fig. 14. The average velocity of the recrystallization front (Cahn-Hagel compensated recrystallization rate - $\dot{\mathrm{G}}_{\mathrm{CH}}$ ) vs differences in locally stored energy ( $\left.\kappa\right)$. Arrows indicate the sense of evolution with time (towards stagnation: $\dot{\mathrm{G}}_{\mathrm{CH}}=0$ ). The triangles represent the $\kappa$ values of S119, which have only been defined for a stagnating recrystallization front (the "plateau"). (a) Median $\kappa$ along the x-axis. (b) Truncated median $\kappa$ along the $x$-axis, where $\kappa$ values $<0.5^{\circ}$ were removed from the distribution. steady decrease of the average KAM (and therefore stored energy) in the sub-structured domain. The grain growth parameters estimated for this sample, and in particular the grain growth exponent, are consistent with the ones observed in normal grain growth models. However, it displays an evolution of the grain boundary roughness and the average $\kappa$ value similar to other samples, suggesting that annealing in this sample is still dominated by recrystallization powered by local differences of stored energy.

\subsection{Grain boundary mobility vs. local stored energy}

To further explore the influence of the stored energy associated to dislocations on the recrystallization kinetics, we plotted the evolution of the average velocity of the recrystallization front (the compensated recrystallization rate, $\dot{G}_{C H}$, see Appendix C3 for the definition) against the evolution of $\kappa$ (Fig. 14a). Several features stand out. First, both values decrease with time in a roughly linear manner, suggesting a correlation between them. The only exception is the first annealing stage in S81, but it is likely due to an artefact caused by an overestimation of $S_{V}$ by including grain boundaries from dynamically recrystallized grains. Second, the paths do not converge, which means that, for a given $\kappa$, the recrystallization front developed different average velocities in the different samples. For instance, an average velocity of migration of the recrystallization front $\left(\dot{G}_{C H}\right)$ of $2.0 \mu \mathrm{m} \cdot \mathrm{s}^{-1}$ is attained at $\kappa=0.55^{\circ} \cdot \mathrm{nm}^{-1}$ in S81, but at $\kappa=0.84^{\circ} \cdot \mathrm{nm}^{-1}$ in S142b. Third, the stagnation of the recrystallization front $\left(\dot{G}_{C H}=0\right)$ is predicted to occur for different average $\kappa$ values (varying between 0.5 and $0.78^{\circ} \cdot \mathrm{nm}^{-1}$ ) in the different samples.

To avoid any noise effect in the estimation of $\kappa$, we also estimate a truncated median by rejecting all $\kappa$ values $<0.5^{\circ} \cdot \mathrm{nm}^{-1}$ from the distribution (Fig. 14b), since such very low $\kappa$ values result from misorientation measurements of the order of the angular resolution of EBSD (see Supplementary Material). Using this approach, all samples with high initial KAMs $\left(>1.2^{\circ}\right)$ roughly converge into a single path, characterized by a stagnation of the recrystallization front at $\kappa \simeq 1^{\circ} \cdot \mathrm{nm}^{-1}$ (Fig. 14b). However, samples with initial KAMs lower than $1^{\circ}$ still follow different paths and should attain stagnation of the recrystallization front at lower $\kappa$ values. This elicits the question as to whether the stored energy $\left(F_{S}\right)$ is the only key factor controlling the velocity of the recrystallization front in AZ31B alloys or if other factors need to be considered. This is particularly true for S107.

\subsection{Crystallography-controlled grain boundary mobility factors}

As the temperature is the same in all experiments, the only intrinsic boundary mobility factors that can explain the variation in recrystallization evolution among samples are crystallographic. To evaluate the influence of these factors, it would be necessary to track the boundary misorientation and textures with time, but this is not possible with 2D experiments, as it is impossible to correlate the migration of grain boundaries to their crystallographic planes. However, in situ monitoring allowed us to discard the occurrence of face-parallel grain boundary migration, leading to the development of crystal facets, and hence boundary migration controlled by specific crystallographic planes.

The lack of systematic changes with time in the misorientation angle distribution along the recrystallization front (Fig. 12b) indicates little to no effect of special grain boundaries on the recrystallization front mobility. This agrees with the lack of a misorientation angle control already observed in cubic-symmetry materials [6,23-27].

The texture changes as a result of recrystallization (Fig. 12a). However, in contrast to previous works [15-17], only the samples deformed with their dominant c-axis along $\mathrm{CD}$ show preferential growth of grains with prismatic planes $\{-12-10\}$ parallel to ED. The dynamically recrystallized grains in these samples already showed a maximum of $\{-12-10\}$ close to ED at deformed state, suggesting that they acted as seeds for recrystallization. The samples deformed with a dominant c-axis along with TD shows markedly different evolutions, characterized by either a slight opening and concentration of the c-axis about ED or a strong weakening of the texture. It can therefore be concluded that, in our experiments, the initial texture and the orientations of the dynamically recrystallized grains control the texture evolution during annealing.

\subsection{Stagnation of the recrystallization front}

Progressive smoothing of grain boundaries during recrystallization was proposed as a stagnation mechanism [44]; however, this mechanism does not apply here as smoothing is observed at RX-RX boundaries (and can therefore explain their stagnation), but not at the recrystallization front, which remains irregular throughout the experiment. In contrast, we found evidence that the decrease in stored energy in the vicinity of the recrystallization front (measured with $\kappa$ ) contributes to the decrease in migration rate in a roughly linear manner. Still, as mentioned previously, stagnation of the recrystallization front occurs at different $\kappa$ for the samples with lower initial stored energy.

This observation might be explained if extrinsic factors played a role along with the decreasing stored energy. The series of in situ EBSD orientation maps and fore-scattered electron images provide no evidence of pinning by secondary particles (Zener pinning) in our samples. Pinning due to solute (impurities) segregation to grain boundaries was previously observed in $\mathrm{Mg}$ alloys during annealing at $350-400{ }^{\circ} \mathrm{C}$ $[22,45]$. Solute segregation is, however, complex to evaluate without direct evidence, as it depends on variables, which are difficult if not impossible to assess from 2D EBSD experiments, such as the boundary plane normal [46] or local boundary velocity $[46,47]$. The hypothesis of a recrystallization front stagnation induced by the accumulation of solutes coupled with a decrease of the stored energy is plausible. However, this would require further testing such as characterizing the density of solute particles at the recrystallization front or comparing the behaviours of pure $\mathrm{Mg}$ and AZ31B alloy under similar conditions. Moreover, to explain the protracted recrystallization in samples with low initial KAMs, impurity levels should significantly differ or solute segregation pinning should be more effective in pinning fast-moving 
boundaries.

Regarding potential free surface artefacts, samples developed no surface oxidation during annealing, so this effect can be discarded. The presence of grain boundary grooving due to electro-polishing [48] was not directly evaluated and there is no previous literature on a potential effect in AZ31B. Grain boundary grooving might lead to a local grain boundary stagnation [49] and explain some off-trend observations such as stuck boundary segments with high $\kappa$ values. In any case, we consider unlikely that these artefacts, which essentially result in local pinning, can cause global stagnation of the recrystallization front.

\subsection{Grain growth}

Previous works on AZ31B provided grain growth exponents typically ranging between 2 and 5 [18,50-52]. The parabolic growth model, for which boundary migration is mainly driven by boundary energy, uses a value of 2 [3]. In contrast, the fitted power-law curves of all samples but $S 107$ provide grain growth exponents between 7 and 18 (Fig. 6, Table 5). Deviation from the parabolic model is to be expected, as recrystallization in AZ31B is far from the one of an ideal, singlephase pure material, due to preferential nucleation and highly anisotropic growth. Materials with higher dislocation content or pinning forces usually display higher $n$ values [3]. We propose therefore that the high $n$ values $(\gg 5$ ) obtained in this work are representative of grain growth rates during dislocation-driven recrystallization.

\section{Conclusions}

For annealing of highly to moderately deformed AZ31B Mg alloys at moderate temperature $\left(\sim 0.62 T_{m}\right)$, we conclude that

- Recrystallization develops by nucleation and growth of substructure-free grains. It develops rapidly but remains incomplete.

- Recrystallization is driven by the stored energy associated with dislocations rather than by grain boundary energy. Evidence for dislocation-driven recrystallization are:

o a strong irregularity (roughness) of the recrystallization front as it progresses in the sub-structured domain;

o a strong correlation between the KAM and the recrystallized fraction throughout annealing;

o a clear preferential consumption of grains with high GKAMs;

$o$ a first-order linear correlation between the $\kappa$ parameter for the stored energy in the vicinity of the recrystallization front and the spatially averaged recrystallization front velocity (Cahn-Hagel compensated velocity).

- Twinning exerts some control on recrystallization by favouring nucleation as inferred from the anomalous behaviour of S107 and, to a lesser extent, S119.

- The decrease in stored energy with time cannot alone explain the incomplete final recrystallization, in particular in the samples with low initial stored energies. A plausible explanation would be a combination of a decrease in the stored energy and solute drag, but confirmation of a possible role of solute drag requires further testing.

- The logistic (Verhulst) growth curve provides a good prediction of the observed evolution of the recrystallization fractions as long as experimental data are available for most of the recrystallization process. This curve is an alternative to traditional recrystallization models to evaluate recrystallization kinetics, and it can be used for both full and incomplete recrystallization.

- The grain growth exponents ( $n$ ) estimated for this experiment are much higher (7-18) than those proposed in previous works on AZ31B Mg alloys. This is attributed to a grain growth driven by stored energy associated with dislocations.

\section{Declaration of competing interest}

The authors declare that they have no known competing financial interests or personal relationships that could have appeared to influence the work reported in this paper.

\section{Acknowledgments}

This work was supported by a postdoctoral fellowship co-funded by the European Union and the Government of the Principality of Asturias (Spain) [grant number ACA17-32] within the Marie Skłodowska-Curie COFUND (FP7) Actions and by the French Agence Nationale de la Recherche DREAM project [grant number ANR-13-BS09-0001-01]. We are grateful to Séverine Girard-Insardi (EMSE Saint-Étienne) and Christophe Nevado (Géosciences Montpellier) whose work was essential for the channel-die deformation experiments and correct preparation of the EBSD samples, respectively. We thank the reviews by two anonymous reviewers for focusing our thinking and improving this contribution.

\section{Data availability}

The raw data required to reproduce these findings are available to download from https://data.mendeley.com/datasets/ttvh2m9r9s/ draft?a $=$ f35092a2-3a42-4b19-a14a-8c25879e6316.

\section{Appendix A. Grain and twin segmentation}

\section{A.1. Grain segmentation using the fast multiscale clustering (FMC) algorithm}

We used the FMC algorithm [31], instead of the more commonly used pixel-to-pixel misorientation thresholding algorithm, because the latter did not produce a satisfactory segmentation of the RX grains due to the strong initial texture of the material, which resulted in frequent low-angle disorientations between adjacent grains (Fig. A1). 

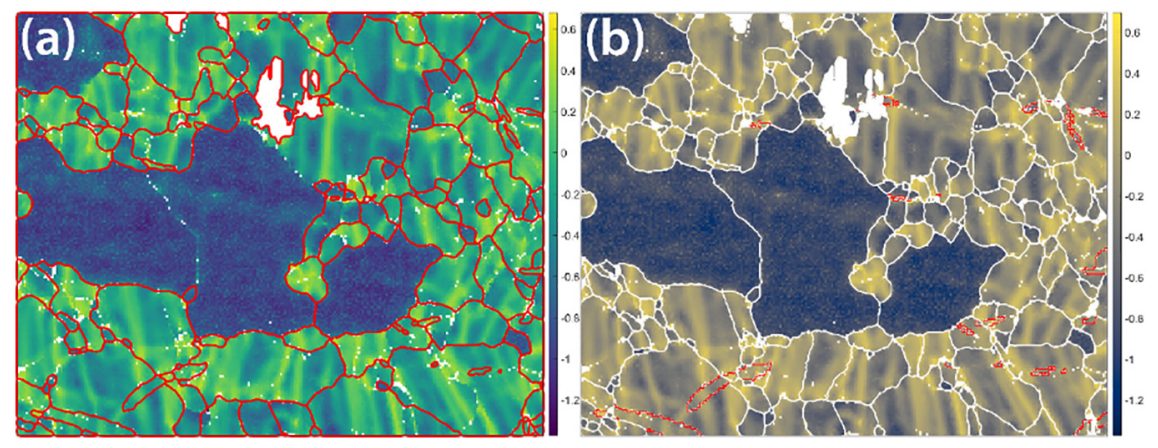

Fig. A1. KAM maps showing grain reconstructions for the same area. (a) Grain reconstruction (in red) using the default pixel-to-pixel misorientation algorithm with a threshold set at $5^{\circ}$. (b) Grain reconstruction of the same area using the FMC algorithm. Note that recrystallized grains (in blue) are better segmented with the latter.

The FMC algorithm uses a hierarchical clustering method that groups pixels with similar orientations, starting from individual data points and iteratively coarsening to form larger clusters. At each step in the hierarchy, every cluster is scored based on the similarity of orientations it contains and on its distinction from neighbouring groups. The highest-scoring groups form the final segmentation of the orientation data and, thus, the grains. The FMC algorithm does not require setting a threshold disorientation value to locate grain boundaries, but a cut-off value to determine the optimum number of clusters in your data. It is therefore a semi-supervised iterative method. Here, the cut-off value was optimized to produce the best grain reconstruction for the recrystallized grains. Occasionally, this approach produced over-segmentation artefacts within the deformed domain, which do not affect the results and conclusions on the evolution of static recrystallization.

\section{A.2. Twin grain boundary fractions}

Twin grain boundary fractions were estimated as:

$100 \times \sum g b_{\text {twins }} / \sum g b_{\text {total }}$

where $\Sigma g b_{\text {twins }}$ corresponds to the total length of the Mg twin grain boundaries and $\Sigma g b_{\text {total }}$ to the total length of magnesium-magnesium grain boundaries.

\section{Appendix B. Grain size}

Apparent (2D) grain sizes were estimated based on EBSD grain segmentation as equivalent circle diameters from the grain section areas as $\mathrm{d}=2 \sqrt{ }(\operatorname{area} / \pi)$. Grains cut by the edges of the maps were not considered. Size properties were estimated using the GrainSizeTools script [53]. Grain size modes are based on the kernel density estimator (KDE) approach [54]. Error bars for the geometric mean were estimated using [55]:

UpperCI $=\exp \left(\mu_{\log }+t \sigma_{\log } / \sqrt{n}\right)$

LowerCI $=\exp \left(\mu_{\log }-t \sigma_{\log } / \sqrt{n}\right)$

where $\mu_{\log }$ and $\sigma_{\log }$ are the arithmetic mean and the standard deviation of the log-transformed data, $n$ the sample size and $t$ the $\mathrm{t}$-score from the $\mathrm{t}$ student distribution at $95 \%$ of certainty (confidence interval).

\section{Appendix C. Grain size and recrystallized fraction kinetics}

\section{C.1. The grain growth model.}

To analyse the evolution of recrystallized grain sizes over time, we used the equation [4]

$D^{n}-D_{0}^{n}=k \mathrm{t}$

where $D$ is the average apparent final grain size, $D_{0}$ the average apparent initial grain size (i.e. the nuclei size), $t$ the time, $n$ a constant that controls the growth rate, and $k$ a growth rate constant with an Arrhenius-type temperature dependence, $k=k_{0}+\exp (-H / R T)[4,56]$. Since we are dealing with nucleation and growth, $D \gg D_{0}$ and thus $D-D_{0} \sim D$. Moreover, the thickness of the samples is several orders of magnitude larger than the average recrystallized grain size at the end of the annealing process; thus we ignore any sample thickness effect [57].

The grain growth function was fitted using logarithmic plots and a least-squares regression algorithm as in the Scipy v.1.3.1 optimize Python package [58] (Python codes are given in Supplementary Material). The correlation coefficient, the two-sided p-value, and the standard error of the regression were estimated.

\section{C.2. The logistic (Verhulst) growth curve}

The logistic function [40] is an equation that produces an S-shaped that properly represents growth limited to a defined maximum value (Fig. C1),

$X_{V}(t)=\frac{L}{1+e^{(m-t) k}}$

The logistic function produces a curve similar to those of the JMAK model [59,60] but includes a parameter (L) to define the asymptotic 
recrystallization fraction (Fig. C1). The logistic function is also differentiable so provides the growth rate at any time.

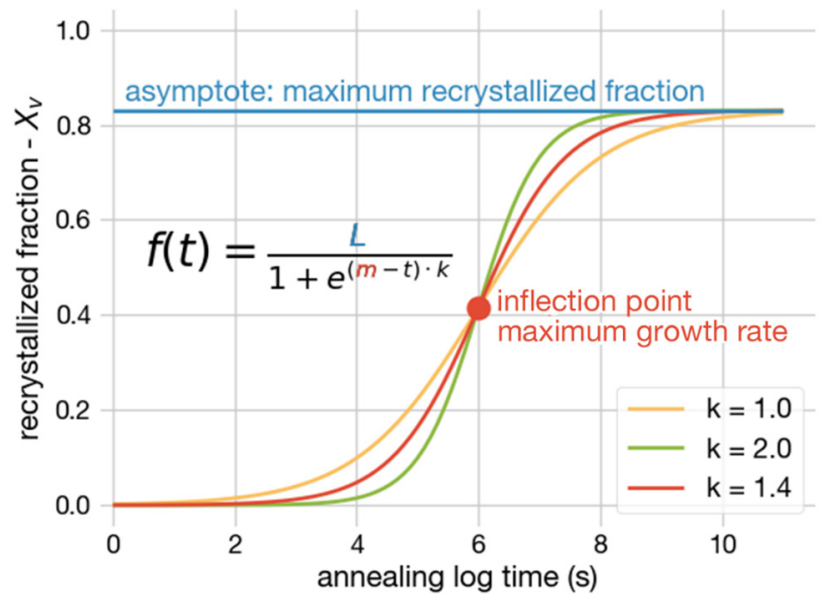

Fig. C1. Logistic (Verhulst) curve used to predict the recrystallization fraction evolution with time. Parameter k controls the shape of the curve (i.e. how the recrystallization rate changes with time), $\mathrm{L}$ the maximum recrystallized fraction, and $\mathrm{m}$ the location (in time) of the inflexion point at which recrystallization reaches its maximum growth rate and $50 \%$ of the maximum recrystallization (low/high $\mathrm{m}$ values indicate fast/slow kinetics).

The logistic function was fitted using a Levenberge-Marquardt algorithm [61] as put in the Scipy (v.1.3.1) optimize Python package [58] (Python codes are given in Supplementary Material). Reported errors are coefficients of variation in percentage at 2-sigma level (i.e. the confidence interval at $95 \%)$.

\section{C.3. Cahn-Hagel interface averaged recrystallization method}

The Cahn-Hagel spatially-averaged interface migration rate method [41] is a method that allows estimating the spatially-averaged speed of the recrystallization front using the following relation:

$G_{C H}=\frac{1}{S_{V}} \frac{d X_{V}}{d t}=\frac{\dot{G}}{S_{V}}$

where $S_{V}$ is the length of the recrystallization front per unit area (i.e. the normalization factor) and $d X_{V} / d t$ the $\mathrm{RX}$ rate $(\dot{G})$.

\section{Appendix D. Supplementary data}

Supplementary data to this article can be found online at https://doi.org/10.1016/j.matchar.2020.110382.

\section{References}

[1] R.D. Doherty, D.A. Hughes, F.J. Humphreys, J.J. Jonas, D. Juul Jensen, M.E. Kassner, W.E. King, T.R. McNelley, H.J. McQueen, A.D. Rollett, Current issues in recrystallization: a review, Mater. Sci. Eng. 238 (1997) 219-274, https://doi.org/ 10.1016/S1369-7021(98)80046-1.

[2] A.D. Rollett, G. Gottstein, L.S. Shvindlerman, D.A. Molodov, Grain boundary mobility - a brief review, Zeitschrift Für Met 95 (2004) 226-229, https://doi.org/10. 3139/146.017938.

[3] F.J. Humphreys, G.S. Rohrer, A.D. Rollett, Recrystallization and Related Annealing Phenomena, Elsevier, 2017, https://www.sciencedirect.com/book/ 9780080982359/recrystallization-and-related-annealing-phenomena , Accessed date: 9 June 2015.

[4] J.E. Burke, D. Turnbull, Recrystallization and grain growth, Prog. Met. Phys. 3 (1952) 220-292, https://doi.org/10.1016/0502-8205(52)90009-9.

[5] F. Haessner, Recrystallization of Metallic Materials, Riederer Verlag, Stuttgart, 1978.

[6] Y.B. Zhang, A. Godfrey, D. Juul Jensen, Local boundary migration during recrystallization in pure aluminium, Scr. Mater. 64 (2011) 331-334, https://doi.org/ 10.1016/j.scriptamat.2010.10.028.

[7] H. Sternlicht, W. Rheinheimer, M.J. Hoffmann, W.D. Kaplan, The mechanism of grain boundary motion in SrTiO3, J. Mater. Sci. 51 (2016) 467-475, https://doi. org/10.1007/s10853-015-9058-1.

[8] K. Lücke, K. Detert, A quantitative theory of grain-boundary motion and recrystallization in metals in the presence of impurities, Acta Metall. 5 (1957) 628-637, https://doi.org/10.1016/0001-6160(57)90109-8.

[9] J.W. Cahn, The impurity-drag effect in grain boundary motion, Acta Metall. 10 (1962) 789-798, https://doi.org/10.1016/0001-6160(62)90092-5.

[10] C.S. Smith, Grains, phases, and interfaces: an interpretation of microstructure, Trans. AIME 175 (1948) 15-51.

[11] E. Nes, N. Ryum, O. Hunderi, On the Zener drag, Acta Metall. 33 (1985) 11-22, https://doi.org/10.1016/0001-6160(85)90214-7.

[12] M.R. Drury, F.J. Humphreys, S.H. White, Large strain deformation studies using polycrystalline magnesium as a rock analogue. Part II: dynamic recrystallisation mechanisms at high temperatures, Phys. Earth Planet. Inter. 40 (1985) 208-222, https://doi.org/10.1016/0031-9201(85)90131-1.

[13] S.H. White, M.R. Drury, S.E. Ion, F.J. Humphreys, Large strain deformation studies using polycrystalline magnesium as a rock analogue. Part I: grain size paleopiezometry in mylonite zones, Phys. Earth Planet. Inter. 40 (1985) 201-207, https://doi. org/10.1016/0031-9201(85)90130-X.

[14] J.H.P. De Bresser, C.J. Peach, J.P. Reijs, C.J. Spiers, On dynamic recrystallization during solid state flow: effects of stress and temperature, Geophys. Res. Lett. 25 (1998) 3457-3460, https://doi.org/10.1029/98GL02690.

[15] S. Yi, H.G. Brokmeier, D. Letzig, Microstructural evolution during the annealing of an extruded AZ31 magnesium alloy, J. Alloys Compd. 506 (2010) 364-371, https:// doi.org/10.1016/j.jallcom.2010.07.008.

[16] H.Y. Chao, H.F. Sun, W.Z. Chen, E.D. Wang, Static recrystallization kinetics of a heavily cold drawn AZ31 magnesium alloy under annealing treatment, Mater. Charact. 62 (2011) 312-320, https://doi.org/10.1016/j.matchar.2011.01.007.

[17] M.T. Pérez-Prado, O.A. Ruano, Texture evolution during annealing of magnesium AZ31 alloy, Scr. Mater. 46 (2002) 149-155, https://doi.org/10.1016/S13596462(01)01212-X.

[18] J.J. Bhattacharyya, S.R. Agnew, G. Muralidharan, Texture enhancement during grain growth of magnesium alloy AZ31B, Acta Mater. 86 (2015) 80-94, https://doi. org/10.1016/j.actamat.2014.12.009.

[19] A. Jäger, P. Lukáč, V. Gärtnerová, J. Haloda, M. Dopita, Influence of annealing on the microstructure of commercial Mg alloy AZ31 after mechanical forming, Mater. Sci. Eng. A 432 (2006) 20-25, https://doi.org/10.1016/j.msea.2006.06.070.

[20] J. Su, M. Sanjari, A.S.H. Kabir, J.J. Jonas, S. Yue, Static recrystallization behavior of magnesium AZ31 alloy subjected to high speed rolling, Mater. Sci. Eng. A 662 (2016) 412-425, https://doi.org/10.1016/j.msea.2016.03.047.

[21] J. Shi, K. Cui, B. Wang, L. Deng, C. Wang, Z. Xu, Q. Li, Effect of initial microstructure on static recrystallization of Mg-3Al-1Zn alloy, Mater. Charact. 129 (2017) 104-113, https://doi.org/10.1016/j.matchar.2017.04.029.

[22] Z.R. Zeng, Y.M. Zhu, S.W. Xu, M.Z. Bian, C.H.J. Davies, N. Birbilis, J.F. Nie, Texture evolution during static recrystallization of cold-rolled magnesium alloys, Acta Mater. 105 (2016) 479-494, https://doi.org/10.1016/j.actamat.2015.12.045.

[23] Y.B. Zhang, A. Godfrey, Q. Liu, W. Liu, D. Juul Jensen, Analysis of the growth of individual grains during recrystallization in pure nickel, Acta Mater. 57 (2009) 
2631-2639, https://doi.org/10.1016/j.actamat.2009.01.039.

[24] G.H. Fan, Y.B. Zhang, J.H. Driver, D. Juul Jensen, Oriented growth during recrystallization revisited in three dimensions, Scr. Mater. 72-73 (2014) 9-12, https://doi.org/10.1016/j.scriptamat.2013.09.031.

[25] Y.B. Zhang, A. Godfrey, D. Juul Jensen, In-situ investigation of local boundary migration during recrystallization, Metall. Mater. Trans. A. 45 (2014) 2899-2905, https://doi.org/10.1007/s11661-014-2222-4.

[26] Y.B. Zhang, J.D. Budai, J.Z. Tischler, W. Liu, R. Xu, E.R. Homer, A. Godfrey, D. Juul Jensen, Boundary migration in a 3D deformed microstructure inside an opaque sample, Sci. Rep. 7 (2017) 1-8, https://doi.org/10.1038/s41598-017-04087-9.

[27] S. Schmidt, S.F. Nielsen, C. Gundlach, L. Margulies, X. Huang, D. Juul Jensen, Watching the growth of bulk grains during recrystallization of deformed metals, Science 305 (80) (2004) 229-232, https://doi.org/10.1126/science.1098627.

[28] C. Maurice, D. Piot, H. Klocker, J.H. Driver, Hot plane strain compression testing of aluminum alloys by channel-die compression, Metall. Mater. Trans. A Phys. Metall. Mater. Sci. 36 (2005) 1039-1047, https://doi.org/10.1007/s11661-005-0297-7.

[29] F. Bachmann, R. Hielscher, H. Schaeben, Texture analysis with MTEX - free and open source software toolbox, Solid State Phenom. 160 (2010) 63-68, https://doi. org/10.4028/www.scientific.net/SSP.160.63.

[30] D. Mainprice, F. Bachmann, R. Hielscher, H. Schaeben, Descriptive tools for the analysis of texture projects with large datasets using MTEX: strength, symmetry and components, Geol. Soc. London, Spec. Publ. 409 (2014) 251-271, https://doi.org/ 10.1144/SP409.8.

[31] C. McMahon, B. Soe, A. Loeb, A. Vemulkar, M. Ferry, L. Bassman, Boundary identification in EBSD data with a generalization of fast multiscale clustering, Ultramicroscopy 133 (2013) 16-25, https://doi.org/10.1016/J.ULTRAMIC.2013. 04.009.

[32] A.J. Wilkinson, D.J. Dingley, G. Meaden, Strain mapping using electron backscatter diffraction, Electron Backscatter Diffr. Mater. Sci, Springer US, Boston, MA, 2009, pp. 231-249, , https://doi.org/10.1007/978-0-387-88136-2 17.

[33] M. Calcagnotto, D. Ponge, E. Demir, D. Raabe, Orientation gradients and geometrically necessary dislocations in ultrafine grained dual-phase steels studied by $2 \mathrm{D}$ and 3D EBSD, Mater. Sci. Eng. A 527 (2010) 2738-2746, https://doi.org/10.1016/ J.MSEA.2010.01.004.

[34] M. Kamaya, Measurement of local plastic strain distribution of stainless steel by electron backscatter diffraction, Mater. Charact. 60 (2009) 125-132, https://doi. org/10.1016/j.matchar.2008.07.010.

[35] A. Godfrey, O.V. Mishin, T. Yu, Characterization and influence of deformation microstructure heterogeneity on recrystallization, IOP Conf. Ser. Mater. Sci. Eng. 89 (2015) 012003, , https://doi.org/10.1088/1757-899X/89/1/012003.

[36] M. Kamaya, Assessment of local deformation using EBSD: quantification of accuracy of measurement and definition of local gradient, Ultramicroscopy 111 (2011) 1189-1199, https://doi.org/10.1016/J.ULTRAMIC.2011.02.004.

[37] S.I. Wright, M.M. Nowell, D.P. Field, A review of strain analysis using electron backscatter diffraction, Microsc. Microanal. 17 (2011) 316-329, https://doi.org/ 10.1017/S1431927611000055.

[38] R. DeHoff, Annealing Processes - Recovery, Recrystallization and Grain Growth, Risø National Laboratory, Roskilde, Denmark, 1986.

[39] R.A. Vandermeer, D. Juul Jensen, Recrystallization in hot vs cold deformed commercial aluminum: a microstructure path comparison, Acta Mater. 51 (2003) 3005-3018, https://doi.org/10.1016/S1359-6454(03)00112-5.

[40] P.-F. Verhulst, Notice sur la loi que la population suit dans son accroissement, Corr. Math. Phys. 10 (1838) 113-121.

[41] J.W. Cahn, W.G. Hagel, Divergent pearlite in a manganese eutectoid steel, Acta Metall. 11 (1963) 561-574, https://doi.org/10.1016/0001-6160(63)90090-7.

[42] S. Piazolo, M. Bestmann, D.J. Prior, C.J. Spiers, Temperature dependent grain boundary migration in deformed-then-annealed material: observations from experimentally deformed synthetic rocksalt, Tectonophysics 427 (2006) 55-71, https://doi.org/10.1016/j.tecto.2006.06.007.

[43] X. Li, P. Yang, L.N. Wang, L. Meng, F. Cui, Orientational analysis of static recrystallization at compression twins in a magnesium alloy AZ31, Mater. Sci. Eng. A 517 (2009) 160-169, https://doi.org/10.1016/j.msea.2009.03.045.

[44] E.A. Holm, S.M. Foiles, How grain growth stops: a mechanism for grain-growth stagnation in pure materials, Science (80) 328 (2010) 1138-1141, https://doi.org/ $10.1126 /$ science.1187833.

[45] J.P. Hadorn, K. Hantzsche, S. Yi, J. Bohlen, D. Letzig, J.A. Wollmershauser, S.R. Agnew, Role of solute in the texture modification during hot deformation of Mg-rare earth alloys, Metall. Mater. Trans. A Phys. Metall. Mater. Sci. 43 (2012) 1347-1362, https://doi.org/10.1007/s11661-011-0923-5.

[46] K. Lücke, H.P. Stüwe, On the theory of impurity controlled grain boundary motion, Acta Metall. 19 (1971) 1087-1099, https://doi.org/10.1016/0001-6160(71) 90041-1.

[47] K. Lücke, H.P. Stüwe, Recovery and Recrystallization of Metals, Wiley, 1963.

[48] P. Sachenko, J.H. Schneibel, W. Zhang, Effect of faceting on the thermal grainboundary grooving of tungsten, Philos. Mag. A Phys. Condens. Matter, Struct. Defects Mech. Prop. 82 (2002) 815-829, https://doi.org/10.1080/ 01418610208243204

[49] G. Gottstein, L.S. Shvindlerman, Grain Boundary Migration in Metals: Thermodynamics, Kinetics, Applications, Taylor \& Francis, 2010.

[50] C.W. Su, L. Lu, M.O. Lai, Recrystallization and grain growth of deformed magnesium alloy, Philos. Mag. 88 (2008) 181-200, https://doi.org/10.1080/ 14786430701805566.

[51] Q. Miao, L. Hu, X. Wang, E. Wang, Grain growth kinetics of a fine-grained AZ31 magnesium alloy produced by hot rolling, J. Alloys Compd. 493 (2010) 87-90, https://doi.org/10.1016/j.jallcom.2009.12.049.

[52] X. Wang, L. Hu, K. Liu, Y. Zhang, Grain growth kinetics of bulk AZ31 magnesium alloy by hot pressing, J. Alloys Compd. 527 (2012) 193-196, https://doi.org/10. 1016/j.jallcom.2012.03.006.

[53] M.A. Lopez-Sanchez, GrainSizeTools: a Python script for grain size analysis and paleopiezometry based on grain size, J. Open Source Softw. 3 (2018) 863, https:// doi.org/10.21105/joss.00863.

[54] M.A. Lopez-Sanchez, S. Llana-Fúnez, An evaluation of different measures of dynamically recrystallized grain size for paleopiezometry or paleowattometry studies, Solid Earth 6 (2015) 475-495, https://doi.org/10.5194/se-6-475-2015.

[55] M.A. Lopez-sanchez, Which average, how many grains, and how to estimate robust confidence intervals in unimodal grain size populations, J. Struct. Geol. 135 (2020) 104042, , https://doi.org/10.1016/j.jsg.2020.104042.

[56] H.N. Murty, Kinetics of grain growth, Philos. Mag. 20 (1969) 855-858, https://doi. org $/ 10.1080 / 14786436908228052$.

[57] R.A. Vandermeer, H. Hu, On the grain growth exponent of pure iron, Acta Metall. Mater. 42 (1994) 3071-3075, https://doi.org/10.1016/0956-7151(94)90404-9.

[58] P. Virtanen, R. Gommers, T.E. Oliphant, M. Haberland, T. Reddy, D. Cournapeau, E. Burovski, P. Peterson, W. Weckesser, J. Bright, S.J. van der Walt, M. Brett, J. Wilson, K.J. Millman, N. Mayorov, A.R.J. Nelson, E. Jones, R. Kern, E. Larson, C.J. Carey, İ. Polat, Y. Feng, E.W. Moore, J. VanderPlas, D. Laxalde, J. Perktold, R. Cimrman, I. Henriksen, E.A. Quintero, C.R. Harris, A.M. Archibald, A.H. Ribeiro, F. Pedregosa, P. van Mulbregt, SciPy 1.0: fundamental algorithms for scientific computing in Python, Nat. Methods (2020), https://doi.org/10.1038/s41592-0190686-2.

[59] A.N. Kolmogorov, On the statistical theory of crystallization of metals [in Russian], Izv. Akad. Nauk SSSR, Ser. Mat. 3 (1937) 355-359.

[60] M. Avrami, Kinetics of phase change. I general theory, J. Chem. Phys. 7 (1939) 1103-1112, https://doi.org/10.1063/1.1750380.

[61] D.W. Marquardt, An algorithm for least-squares estimation of nonlinear parameters, J. Soc. Ind. Appl. Math. 11 (1963) 431-441, https://doi.org/10.1137/0111030. 